\title{
Review \\ A Bibliometric Analysis of Drought Indices, Risk, and Forecast as Components of Drought Early Warning Systems
}

\author{
Gokhan Yildirim ${ }^{1}$, Ataur Rahman ${ }^{1, *}$ and Vijay P. Singh ${ }^{2,3}$ \\ 1 School of Engineering, Design and Built Environment, Penrith Campus, Western Sydney University, \\ Sydney 2747, Australia; g.yildirim@westernsydney.edu.au \\ 2 Department of Biological and Agricultural Engineering, Texas A \& M University, College Station, \\ TX 77843-2117, USA; Vijay.Singh@ag.tamu.edu \\ 3 Zachry Department of Civil \& Environmental Engineering, Texas A \& M University, College Station, \\ TX 77843-2117, USA \\ * Correspondence: a.rahman@westernsydney.edu.au
}

Citation: Yildirim, G.; Rahman, A.; Singh, V.P. A Bibliometric Analysis of Drought Indices, Risk, and Forecast as Components of Drought Early Warning Systems. Water 2022, 14, 253. https://doi.org/10.3390/w14020253

Academic Editor: Maria Mimikou

Received: 11 December 2021

Accepted: 12 January 2022

Published: 16 January 2022

Publisher's Note: MDPI stays neutral with regard to jurisdictional claims in published maps and institutional affiliations.

Copyright: (c) 2022 by the authors. Licensee MDPI, Basel, Switzerland. This article is an open access article distributed under the terms and conditions of the Creative Commons Attribution (CC BY) license (https:// creativecommons.org/licenses/by/ $4.0 /)$.

\begin{abstract}
In this study, we apply a bibliometric analysis to characterize publication data on droughts, mainly focusing on drought indices (DIs), drought risk (DR), and drought forecast (DF). Data on publications on these selected topics were obtained through the Scopus database, covering the period from 1963 to June 2021. The DI-related publications, based on meteorological, soil moisture, hydrological, remote sensing, and composite/modeled Dis, accounted for $57 \%, 8 \%, 4 \%$, 29\%, and $2 \%$ of the scientific sources, respectively. DI-related studies showed a notable increase since the 1990s, due perhaps to a higher number of major droughts during the last three decades. It was found that USA and China were the two leading countries in terms of publication count and academic influence on the DI, DR, and DF studies. A network analysis of the country of residence of co-authors on DR and DF research highlighted the top three countries, which were the USA, China, and the United Kingdom. The most productive journal for the DI studies was found to be the International Journal of Climatology, whereas Natural Hazards was identified as the first-ranked journal for the DR and DF studies. In relation to individual researchers, Singh VP from the USA was found to be the most prolific author, having the greatest academic influence on DF study, whereas Zhang $Q$ from China was identified as the most productive author on DR study. This bibliometric analysis reveals that further research is needed on droughts in the areas of risk management, water management, and drought management. This review maps trends of previous research in drought science, covering several important aspects, such as drought indices, geographic regions, authors and their collaboration paths, and sub-topics of interest. This article is expected to serve as an index of the current state of knowledge on drought warning systems and as guidance for future research needs.
\end{abstract}

Keywords: drought indices; drought risk; drought forecast; bibliometric analysis; scientometrics

\section{Introduction}

Drought is a natural slow-onset phenomenon with major direct or indirect impacts on natural systems, the economy, and human health [1,2]. In recent decades, the severity and spatial coverage of droughts have been increasing due to climate change. Most of the previous famines can be linked to droughts [3]. Due to the complex nature of drought, it has no standard definition that works under all possible circumstances [4]. Generally, drought can be expressed as a deficit in precipitation compared to the long-term mean $[5,6]$. This is regarded as an operational definition [7]. Droughts are classified into four major groups by Wilhite and Glantz [7]: (i) meteorological, deficiency in precipitation; (ii) agricultural, lack of soil moisture; (iii) hydrological, reduction in streamflow; and (iv) socioeconomical, inability to meet water demands. Drought types are characterized based on their severity, frequency, duration, and areal extent [8]. Drought indicators or indices (DIs) are commonly applied to track a drought and to identify its characteristics in terms of duration (onset and 
end), severity, and location. The selection of a drought index/indicator is important for drought monitoring. A variety of indicators/indices is needed to monitor different aspects of drought.

Efficiency and accuracy of hydro-meteorological monitoring are essential inputs for the identification of risk and a drought early warning system (DEWS). A DEWS plays a key role in drought preparedness [9-11] and has monitoring and forecasting components so that it can be used to tackle drought at an early stage and to devise actions within a drought risk management plan as a means of reducing the likely losses [12]. Therefore, describing the overall trends of the development of drought monitoring, drought risk, and drought forecast studies are important for DEWSs, researchers, planners, and decision-makers.

There have been several reviews on various aspects of droughts. For example, Hagenlocher et al. [13] presented a systematic review on drought vulnerability and risk conceptualization. They found that only $10 \%$ of the studies developed future scenarios of drought risk. Orimoloye et al. [14] attempted a systematic mapping of disaster risk management, whereas Orimoloye et al. [15] focused on the spatial assessment of drought disasters, vulnerability, severity, and water shortages for developing a potential drought mitigation strategy. Kchouk et al. [16] investigated 32 drought indices but did not include composite (or modeled) droughts. Mishra and Singh (2010) presented a comprehensive review on droughts.

Although there have been several reviews on droughts, as noted above, more reviews are needed in terms of trends in investigations at the country level on the quality and quantity of academic outputs, research methods, country-wise collaborations, author-wise collaborations, and the geographical distribution of studies in order to understand the evolution of drought, which has become more frequent and severe in recent years due to climate change. Therefore, we applied a bibliometric analysis, an important quantitative analysis tool [17,18], to three key components of the DEWS: drought indicators/indices (DIs), drought risk (DR), and drought forecast (DF). Our objective is to fill the current knowledge gap in the existing drought literature, as follows and further explained in Section 2. After refining the scope, we apply a bibliometric analysis in two different stages for DI-, DR-, and DF-related studies. In the first stage, we investigate the current research situation in terms of DI, DR, and DF studies individually. In the second stage, we merge the duplicates of DI studies using the bibliometrix R-package [19] to obtain a number of studies, and then we combine the DR and DF studies (DR_DF). The main purpose for this 'combine/merge' approach is to eliminate the same articles/authors that contain more than one DI (e.g., SPI and PDSI). Similarly, some authors could have addressed drought risk and forecast in the same article. Addressing the studies individually and when merged allows us to interpret the numbers and trends in each field and highlight countries' and authors' productivities and their collaboration paths. It should be noted that this study does not aim to recommend the 'best' drought index. DIs were chosen, based on the specific characteristics of drought, regional characteristics, or purpose of monitoring. This paper is expected to exhibit the scientific progress in DI, DR, and DF studies and their evolution in drought research in order to guide possible future work.

\section{Materials and Methods}

The adopted research methodology is based on the principle that a thorough bibliometric analysis on the overall trends of development of drought monitoring, drought risk, and drought forecast studies is capable of benchmarking the current state of knowledge on drought warning systems and providing guidance on further research needs in droughts. Based on this principle, this study is conducted by following standard bibliometric analysis, as illustrated in Figure 1 and explained in this section. The adopted methodological approach consists of the following four steps: (1) design of study, (2) data analysis, (3) refined scope, and (4) data visualization. Figure 1 presents the workflow of the bibliometric analysis adopted in this study. 

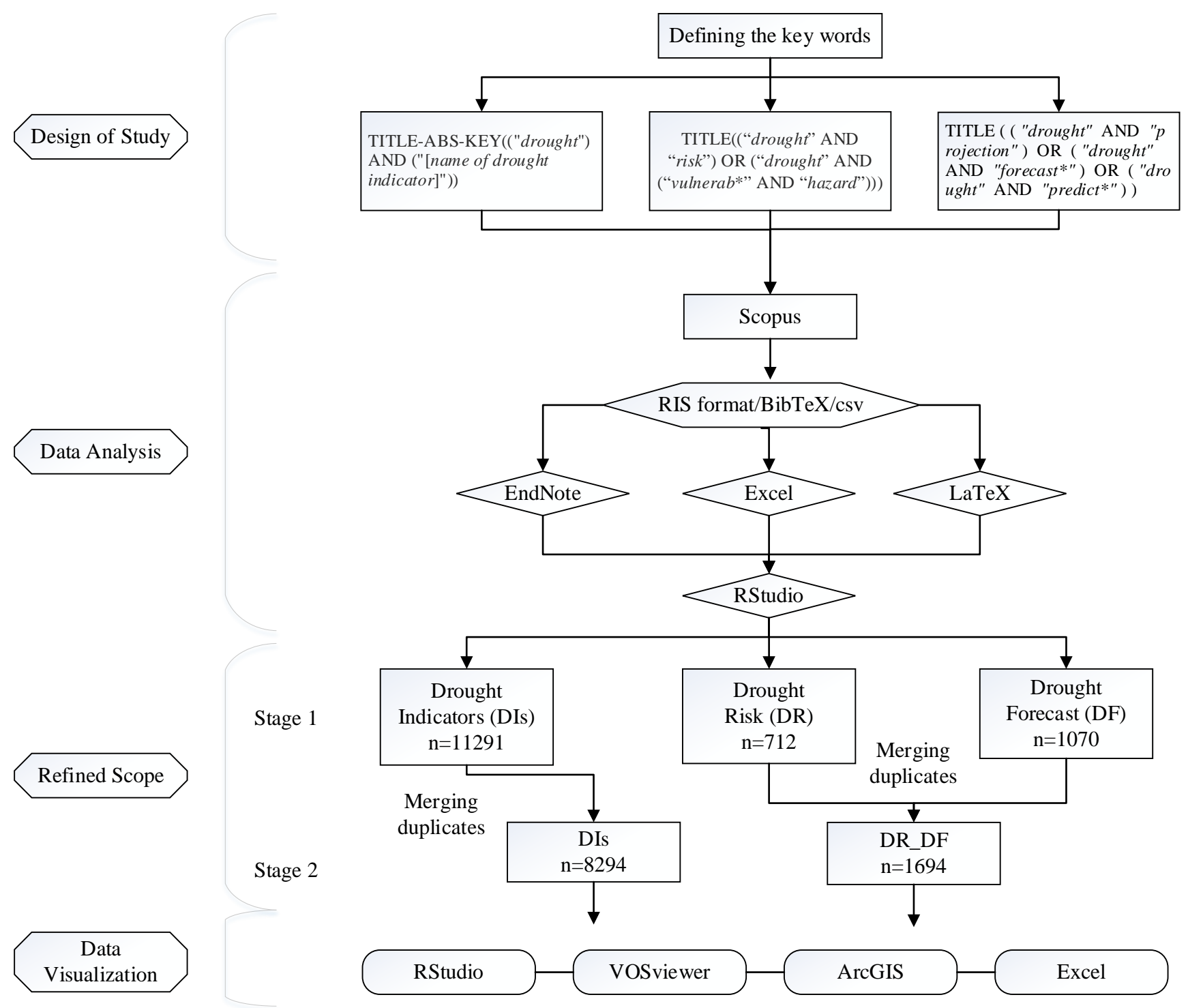

Figure 1. Workflow of adopted bibliometric analysis.

\subsection{Design of Study}

This study investigates the three key components of drought early warning systems (DEWS), which are drought monitoring, risk, and forecast. Published documents on drought indices (DIs), drought risk (DR), and drought forecast (DF) were obtained through the Scopus database (http:/ / www.scopus.com, accessed on 30 June 2021), covering the period from 1963 to June 2021.

\subsubsection{Drought Monitoring}

Drought monitoring requires a variety of indicators, encompassing meteorological, hydrological, soil moisture (or agricultural), and socioeconomic aspects that characterize information on potential drought or deficiency of water. We addressed the most wellknown and/or frequently used drought indicators in scientific drought studies. For this purpose, we selected 50 drought indicators/indices (DIs), which are also given in the World Meteorological Organization (WMO) and Global Water Partnership (GWP) [12] guidelines. The selected DIs do not include socioeconomic and environmental factors (e.g., drought-related impacts). The indices were categorized into five groups: meteorological (22 indices), hydrological (8 indices), soil moisture (or agricultural) (4 indices), remote sensing (11 indices), and composite or modeled (5 indices). 
A query for the selected DIs was identified as: ("drought") AND ("[name of drought indicator]" OR "[abbreviation of drought indicator]") in the title (TITLE), abstract (ABS), and authors' keywords (KEY). As an illustration, TITLE-ABS-KEY (("drought") AND ("SPI" OR "Standardized Precipitation Index")) was the query used for search in the Scopus database for the SPI. This query was applied to each DI individually. However, we avoided using some abbreviations of drought indices, such as DRI (Drought Reconnaissance Index), since DRI may refer to 'Drought Risk Index', which is not a drought indicator. The Drought Risk Index is obtained by multiplying 'Drought Hazard Index' and 'Drought Vulnerability Index' to estimate drought risk.

\subsubsection{Drought Risk}

Risk is the product of both drought hazard and vulnerability [4]. Therefore, keywords were designed based on this definition. Unlike the drought monitoring query, we searched for the selected keywords in 'title' only, similar to Hagenlocher et al. [13]. The reason was that authors might choose 'risk', 'hazard', or 'vulnerability' as a keyword or mention in the abstract in their studies, although the study may not focus on drought risk. The query for drought risk (DR) studies was established as: TITLE (("drought" AND "risk") OR ("drought" AND ("vulnerab*" AND “hazard"))). The keyword "vulnerab*" may represent vulnerability or vulnerable.

\subsubsection{Drought Forecasting}

Although there are different methods for drought forecasting, such as regression models, hybrid models, and neural network models [20], these methods are also used in other forecasting studies, such as flood studies. Therefore, using keywords such as 'drought prediction' or 'drought projection' to explore drought forecasting publications gives more robust results. Moreover, similar to the 'drought risk' database search, we searched for the selected keywords in 'title' only. The query for drought forecast (DF) studies was described as: TITLE (("drought" AND "projection") OR ("drought" AND "forecast") OR ("drought" AND "predict*")).

\subsection{Data Analysis}

The Scopus database, which includes a large number of peer-reviewed publications, such as journals, conference proceedings, and scholarly book chapters, was used to search for scientific publications of interest. Furthermore, Scopus allows us to download 2000 documents at once, whereas Web of Science allows us to instantaneously download only 500 documents. We, therefore, searched for each of the queries in the Scopus database. The search criteria, which were limited to source types (e.g., journals, conference proceedings papers, and book chapters), language (English), and time span (1963 to June 2021 included), were applied to all the queries.

Data were downloaded in three different formats-RIS format, BibTeX, and csv-for analysis. The downloaded data included citation information (authors, title, citation count, and source), bibliographical information (affiliations, publisher, and language), abstract and keywords (author keywords and index keywords), and other information (conference information and references). EndNote, Excel 2016, Latex, and Rstudio were used in addition to the bibliometrix R-package [19] to analyze data. EndNote, Excel 2016, and the bibliometrix R-package were used to cross-check duplications and inconsistencies (e.g., misspellings and variant names) in the documents. Latex was used (if needed) to convert some data from one format to another.

\subsection{Refined Scope}

Drought monitoring, which involves using drought indicators/indices (DIs) in this study, was addressed in two stages. First, published documents were found for each DI individually, and, in total, 11,291 documents were identified. Details of each DI, such as the total number of studies, the most applied countries, the number of countries using 
the index, and time span, were noted. Second, these documents were merged via the bibliometrix R-package [19], and 8294 documents were obtained from 1424 sources that were used to explore global statistics in terms of attributes such as author collaborations, number of publications, country of collaboration, and co-citations.

On the other hand, the total number of documents was 712 and 1070 for the DR and DF studies, respectively. The procedure applied to the DI studies was also applied to the DR and DF studies. First, the DR and DF publications were investigated individually, and then they were combined for analysis, based on 1694 merged documents (DR_DF) from 648 sources. All in all, three different components of the DEWS were examined.

\subsection{Data Visualization}

There are numerous tools for bibliometric analysis to prepare a science map of different results, and some of them are as follows: CiteSpace, BibExcel, VOSviewer, SciMAT, CitNetExplorer, and bibliometrix R-package [19,21-25]. VOSviewer, a free java application, allows us to analyze and visualize citation networks of scientific publications. It is useful for representing and interpreting large bibliometric maps [21]. In this study, we used the bibliometrix R-package 3.1.4 [19] in the Rstudio environment (https:/ / www.rstudio.com/, accessed on 30 June 2021) and VOSviewer 1.6.16 [21], ArcGIS 10.6.1 (https:/ / www.esri.com/, accessed on 16 July 2021), and Excel 2016 for bibliometric analysis.

\section{Results and Discussion}

This section is organized into two main parts. First, results of data analysis of drought indicators/indices (DIs) are presented. Second, the results of the data analysis of DR and DF are presented.

\subsection{Drought Indices}

Figure 2 presents the proportions of DIs for five different categories: meteorological, soil moisture (agricultural), hydrological, remote sensing, and composite (or modeled). The tree map of DIs (Figure 2) clearly illustrates that the most published documents belong to the meteorological category, whereas the least published documents were reported for composite or modeled DIs. The percentages of documents (out of 11,291 publications) were $57 \%, 8 \%, 4 \%, 29 \%$, and $2 \%$ related to meteorological, soil moisture, hydrological, remote sensing, and composite/modeled DIs, respectively. The most notable DIs in terms of the number of published documents were the Standardized Precipitation Index (SPI), the Normalized Difference Vegetation Index (NDVI), the Palmer Drought Severity Index (PDSI), and the Standardized Precipitation Evapotranspiration Index (SPEI), with 2483 (22\%), 2023 $(17.9 \%), 1245(11 \%)$, and $1207(10.7 \%)$ publications (percentages), respectively. The total number of documents on hydrological DIs was 424 , which was $4 \%$ of total publications in terms of all types of DIs. There were fewer applications of hydrological DIs in AustraliaOceania, Middle-East and North Africa, and Sub-Saharan Africa than in other regions [16]. This could be due to a lack of interest by researchers rather than an absence of drought in these regions. The most popular indicator in the hydrological category was the Streamflow Drought Index (SDI), followed by the Standardized Streamflow Index (SSFI), with 185 and 89 publications, respectively. The most popular soil moisture indicator was Soil Water Storage (SWS) which captured 680 publications across 62 different countries (Table S1). In terms of soil moisture, Australia-Oceania was the leading region [16]. Composite/modeled DIs, which became popular in the mid-2000s, captured the least number of publications (239 documents) compared to the other four categories. The most widely cited indices-DIs, SPI, NDVI, SPEI, SWS, PDSI, the Aridity Index (AI), the Rainfall Anomaly Index (RAI), SDI, and the Vegetation Condition Index (VCI) - were used in 85, 76, 68, 62, 57, 43, 39, 39, and 39 countries around the world, respectively. The DI studies showed an increase after the 1990s, for example, 35 out of 50 DIs were published after the 1990s. 


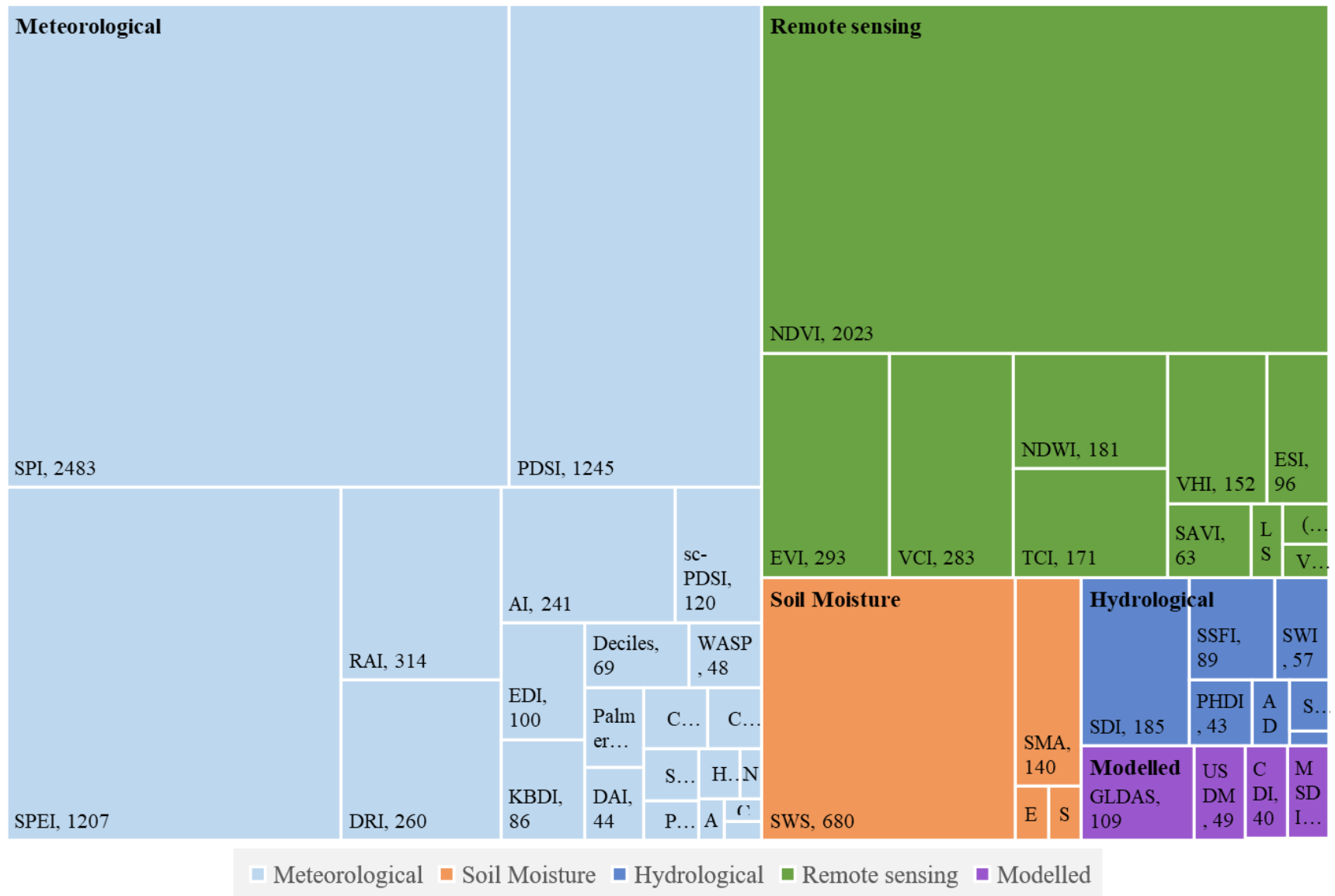

Figure 2. Types of droughts and DIs based on 11,291 documents.

There were several factors that affected the selection and use of DIs, such as data availability, missing data, availability of a code or program to use the index, multiple inputs for calculation, and complexity of calculation. The most complex indices/indicators were not the best ones to apply in drought studies. Visualization of published DIs in terms of the types of DIs and ease of use with their document numbers can help researchers compare them. A Sankey diagram (Figure 3) was prepared to illustrate the most used DIs from each category and their 'ease of use'. Details of the method of classification based on the 'ease of use' can be found in the WMO and GWP (2016). The top three DIs, which captured the highest number of publications, were selected from meteorological, soil moisture ( 2 indicators selected), hydrological, remote sensing, and composite/modeled indicators to prepare the 'alluvial diagram'.

Figure 3 shows that nodes of 'ease of use' are decreasing while the difficulty level of DIs is increasing. The total number of publications was 5280, 2923, and 680 at levels 1, 2, and 3 ease of use, respectively (based on the selected indicators in Figure 3). This result shows that the 'ease of use' of a drought index is one of the main criteria in choosing an index in addition to its reliability. It was noted that the simplicity of an index did not mean it was the best index to use.

The most popular DIs-SPI, PDSI, and SPEI-covered 38.5\%, 19.5\%, and 18.7\%, respectively, of meteorological drought studies in terms of total publications. The NDVI was the most dominant index, which consisted of $60.9 \%$ of remote sensing studies. Figure 4 presents the published documents by year for the most-used DIs based on more than 1000 publications. 


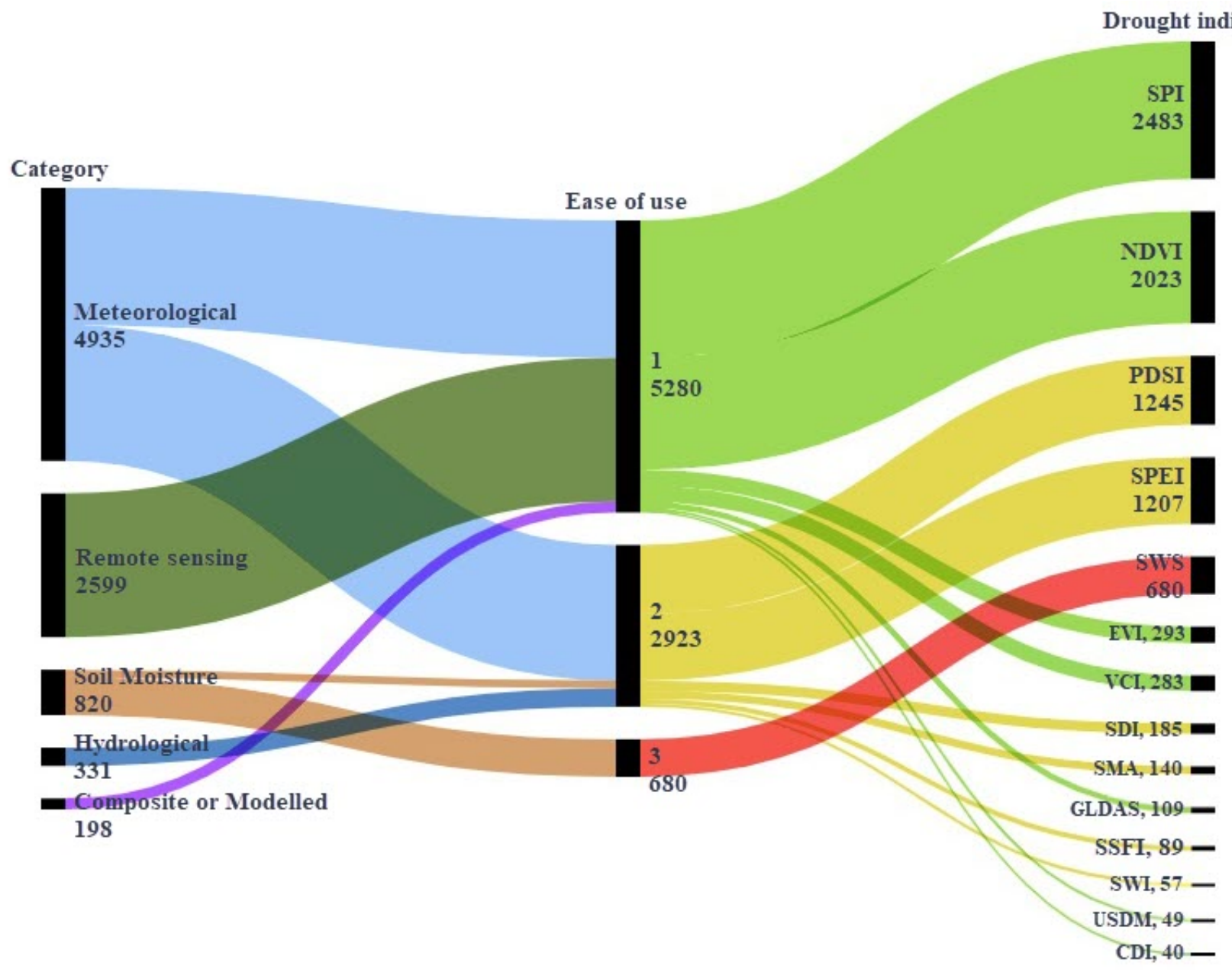

Figure 3. Sankey diagram of category, ease of use, and the most used DIs. The 'ease of use' classification shows that the difficulty level is increasing from 1 to 3 . The number under each category gives the total publications in that node.

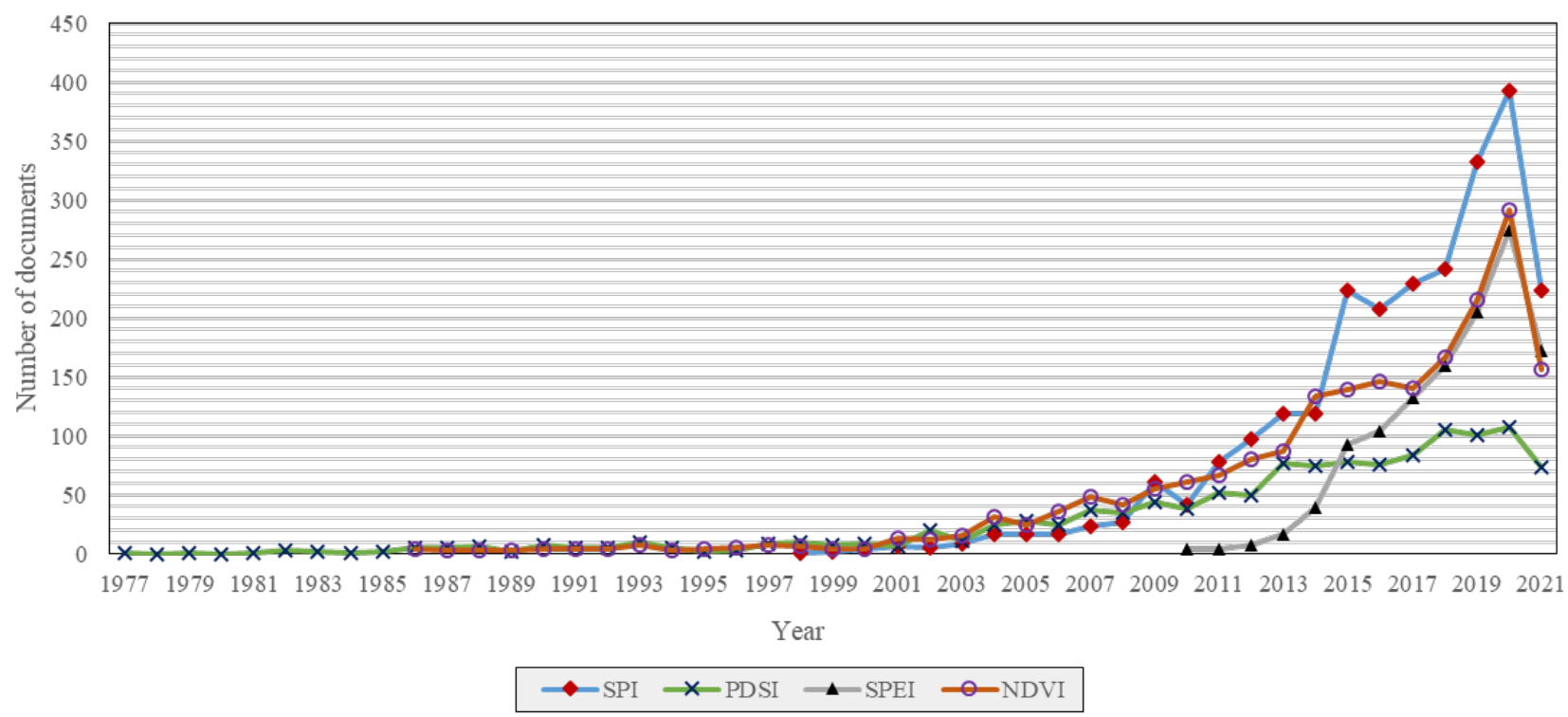

Figure 4. Documents by year for SPI (1998-June 2021), PDSI (1977-June 2021), SPEI (2010-June 2021), and NDVI (1986-June 2021). 
The PDSI that had the longest records of meteorological DIs did not show a notable increasing trend over time. The highest number of documents were published in 2018, 2019, and 2020, being 105, 101, and 107 publications, respectively. The PDSI uses precipitation, temperature, and available water content as input data [26]. Figure 4 shows that the PDSI was not preferred compared to other meteorological DIs due to its complexity of calculation and several other limitations, including (i) the need for serially completed data, (ii) the PDSI being slow to respond to developing and diminishing droughts, (iii) not being useful for identifying a rapid emerging drought due to its lag time, (iv) drought classifications (e.g., "extreme" or "severe") of PDSI values varying widely from one location to another [27-32]. On the other hand, the popularity of SPI, SPEI, and NDVI increased over the period. The SPEI was introduced in 2010 by Vicente-Serrano et al. [33] to overcome the limitations of current DIs. Precipitation and temperature were input data for the SPEI. One of the main advantages of the SPEI is that it is applicable in future climate models under various future scenarios. The SPEI showed the steepest increasing trend when compared to other indices (Figure 4). The NDVI [34] uses satellite data to identify and monitor the effects of drought on agriculture. The SPI was proposed by McKee et al. [35] to monitor meteorological drought by using precipitation data as input. Similar to other DIs, the SPI has both advantages and disadvantages, and more details on this can be found in Mishra and Singh [31]. An abrupt change was detected in 2010 for SPI-related studies. An increasing trend can be seen after 2010 for the SPI (Figure 4). National meteorological and hydrological services (NMHSs) were encouraged to use the SPI to characterize meteorological drought. It was recommended by the WMO in 2009 to take the necessary steps in drought management globally using the SPI [36]. The average number of published documents by year for the SPI, SPEI, NDVI, and PDSI was found to be 104, 101, 56, and 28, respectively.

Figure 5 illustrates the word cloud of frequently occurring keywords plus in DI studies. Keywords plus are index terms obtained by a computer algorithm based on frequent words (more than once) in the titles and the reference list of documents. The use of keywords plus helps capture a document's content with greater variety and depth in bibliometric analysis [37] since keywords plus comprise the majority of author keywords [38]. Keywords plus have been widely used to identify gaps or research trends in different scientific studies $[14,39,40]$.

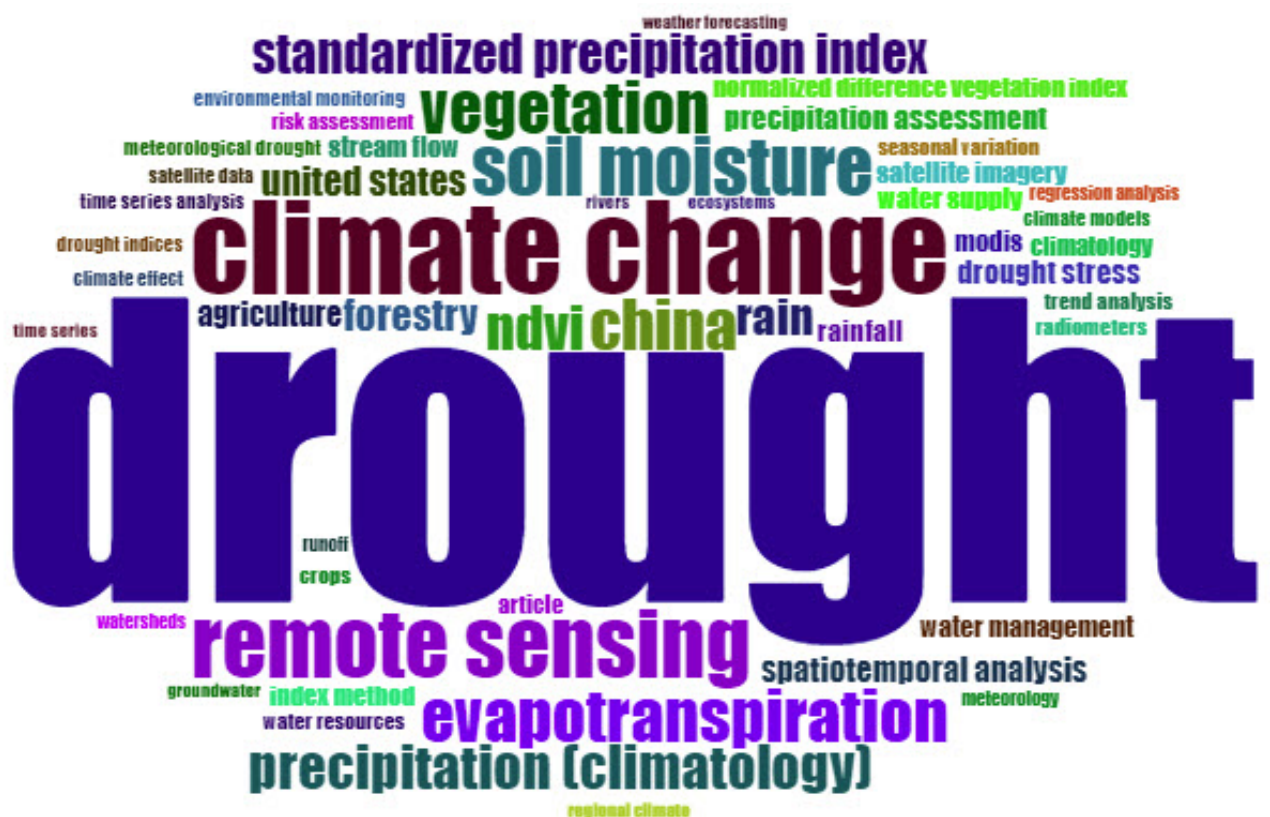

Figure 5. Word cloud for DIs in terms of keywords plus from 8294 merged DI publications. 
Bigger key word size and bold font emphasize the frequency and strength of DI sources (Figure 5). The word cloud represents visually the most frequent words used in relevant studies and helps identify the more (or less) important ones. The most dominant keywords plus were drought $(n=7137)$, climate change $(n=2202)$, remote sensing $(n=1612)$, soil moisture $(n=1370)$, evapotranspiration $(n=1237)$, vegetation $(n=1219)$, China $(n=1181)$, precipitation (climatology) $(n=1046)$, NDVI $(n=1038)$, and standardized precipitation index $(n=941)$ in the DI-related studies.

Figure 6 and Table 1 present the ranking of the top-20 countries in total citations and the top publication category for DI studies, respectively. The quantity of publications is an essential indicator to assess the development trend in a specific field [17]. Therefore, a country's research strength in a particular field to a certain extent can be reflected by its number of publications; however, it does not indicate the frequency and intensity of droughts in the given country. It can be seen that the USA had the highest total citations of 62,011 (Figure 6), whereas China was the first-ranked country in terms of the top publications, with 1694 published documents (Table 1). According to the total citations, China $(n=28,268)$, Spain $(n=13,808)$, India $(n=6229)$, and Australia $(n=5788)$ were the countries that followed the USA, respectively (Figure 6). In terms of top publications, the USA $(n=1372)$, India $(n=393)$, Iran $(n=323)$ and Spain $(n=290)$ were recorded as the highest after China, in that order. On the other hand, average article citations exhibited different consequences. For instance, Switzerland $(\bar{n}=80.5)$ was the first-ranked country in terms of average article citation, whereas China was placed fifteenth, with 16.69 average article citations. In accordance with average article citations, Japan $(\bar{n}=57.22)$, Spain $(\bar{n}=47.61)$, the USA $(\bar{n}=45.20)$, and the United Kingdom $(\bar{n}=44.47)$ were the countries after Switzerland, respectively. There is no doubt that the number of publications has a direct link with the average number of article citations. All in all, Figure 6 and Table 1 show that the USA and China were two leading countries in terms of total citations, number of publications, frequency of publications, single country publications (SCPs), and multiple country publications (MCPs).

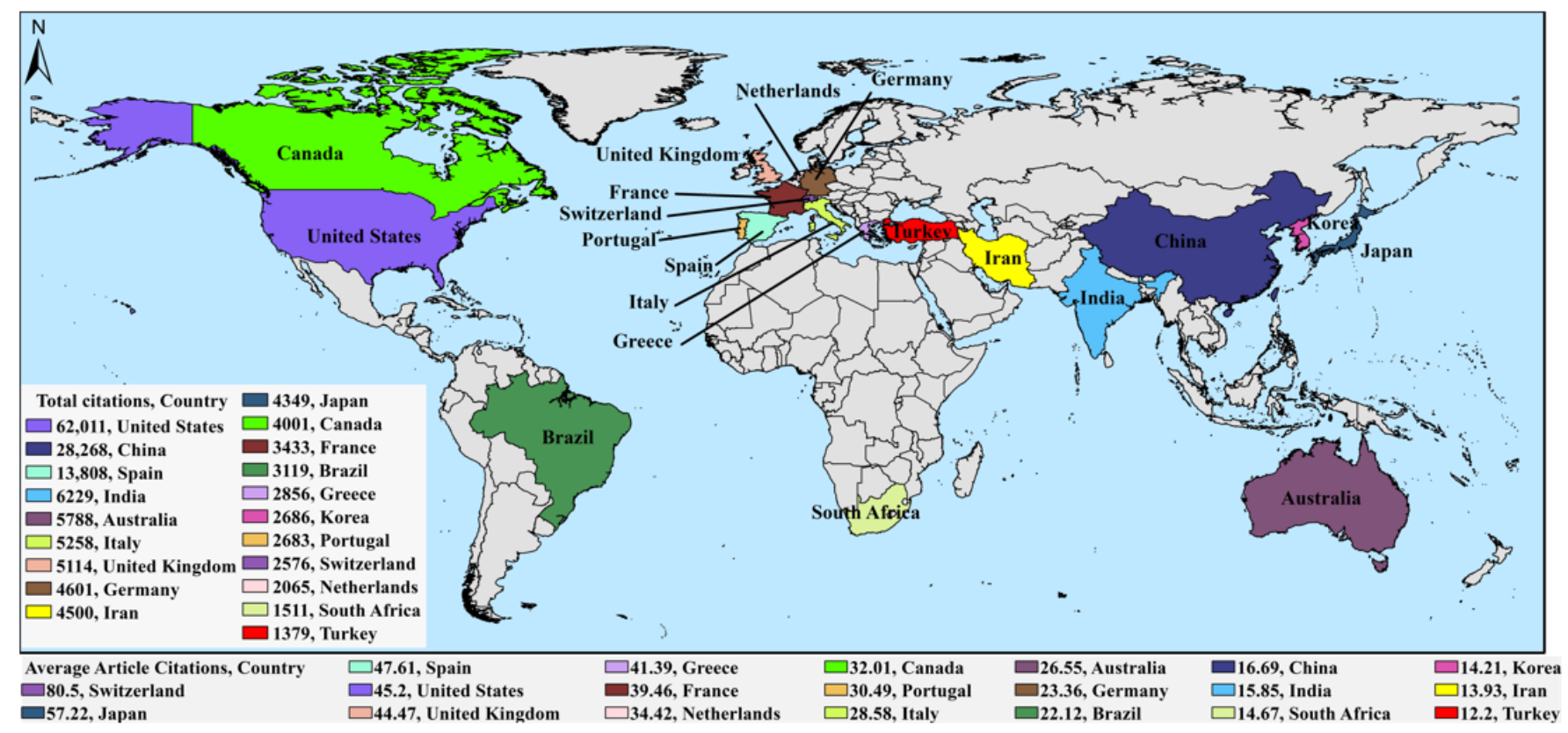

Figure 6. Geographical distribution of the most cited countries based on DI studies. 
Table 1. Top publications per country based on the corresponding author's countries in DI studies.

\begin{tabular}{ccccccc}
\hline Rank & Country & Publications & Freq $\mathbf{( \% )}$ & SCP & MCP & MCP_Ratio \\
\hline 1 & China & 1694 & 24.01 & 1685 & 9 & 0.0053 \\
2 & USA & 1372 & 19.44 & 1366 & 6 & 0.0044 \\
3 & India & 393 & 5.57 & 390 & 3 & 0.0076 \\
4 & Iran & 323 & 4.58 & 318 & 5 & 0.0155 \\
5 & Spain & 290 & 4.11 & 287 & 3 & 0.0103 \\
6 & Australia & 218 & 3.09 & 217 & 1 & 0.0046 \\
7 & Germany & 197 & 2.79 & 196 & 1 & 0.0051 \\
8 & Korea & 189 & 2.68 & 188 & 1 & 0.0053 \\
9 & Italy & 184 & 2.61 & 184 & 0 & 0.0000 \\
10 & Brazil & 141 & 2.00 & 141 & 0 & 0.0000 \\
11 & Canada & 125 & 1.77 & 125 & 0 & 0.0000 \\
12 & United Kingdom & 115 & 1.63 & 115 & 0 & 0.0000 \\
13 & Turkey & 113 & 1.60 & 111 & 2 & 0.0177 \\
14 & South Africa & 103 & 1.46 & 102 & 1 & 0.0097 \\
15 & Portugal & 88 & 1.25 & 87 & 1 & 0.0114 \\
16 & France & 87 & 1.23 & 84 & 3 & 0.0345 \\
17 & Japan & 76 & 1.08 & 72 & 4 & 0.0526 \\
18 & Greece & 69 & 0.98 & 69 & 0 & 0.0000 \\
19 & Mexico & 67 & 0.95 & 67 & 0 & 0.0000 \\
20 & Netherlands & 60 & 0.85 & 59 & 1 & 0.0167 \\
\hline
\end{tabular}

Note: SCP refers to single country publications; MCP refers to multiple country publications; MCP_Ratio is the ratio of the MCPs to the number of publications.

SCPs and MCPs refer to the international collaboration of authors in the DI studies. SCP represents publications done by authors who belonged to the same country, whereas $\mathrm{MCP}$ represents that the publications that were written by authors belonging to different countries. Academic collaboration on an inter-country/international collaboration level is an essential element to evaluate academic development in any specific field.

The most related journals, with their Hirsch-index (H-index), g-index, number of publications, publication ratio (PR), total citations, and citations per publication (CPP), are presented in Table 2. The H-index was developed by Hirsch [41] to quantify and evaluate academic achievements. Simply, the H-index is a journal's (or author's) number of publications (h), each of which has been cited in other papers at least $\mathrm{H}$ times. A higher $\mathrm{H}$-index shows a greater academic impact. Hence, the H-index is an important parameter to evaluate the quality and quantity of academic studies in any bibliometric analysis $[17,42]$. The g-index was introduced as an improvement of the $\mathrm{H}$-index by Egghe [43] in order to measure the global citation performance of a set of articles. Costas and Bordons [44] noted that the g-index was more sensitive than the $\mathrm{H}$-index and that these indices complement each other.

From the analysis of 1424 journals, the most productive journals, in the top 20, based on the DI studies, are shown in Table 2. The number of publications listed in the top 20 journals was $31.7 \%$ of the total. The International Journal of Climatology was the leading journal out of 1424 journals. It had published 261 articles and accounted for $3.15 \%$ of the total publications. In terms of CPP, the Journal of Climate's ranking was much higher than the rest of the journals. Moreover, it had the highest total citation and the second-highest g-index of 99 articles. Although Remote Sensing was the second most productive journal in terms of the number of publications, its total citations and CPP were below the average of the top 20 journals because of its late first issue (2010).

Factorial analysis of the co-occurrences of keywords plus was performed through the multiple correspondence analysis (MCA) [45-47] to obtain a conceptual structure map [48] of the DI studies (Figure 7). The more similar the words in distribution, the closer to each other they are mapped in a two-dimensional space based on the relative positions of points (keywords). Three clusters were generated: Cluster 1-in greenhighlights the meteorological drought, drought indices, and streamflow; Cluster 2-in 
blue-identifies remote-sensing-related studies; and Cluster 3-in red-highlights the other frequent keywords plus, such as water supply, climate change, water management, and climate models.

Table 2. Most productive sources for DIs. (TP is the number of total publications; PR (\%) is the percentage of the number of one journal's publications to the total number of publications; TC is total citation; CPP is the citations per publication, PY_start is the year of the first issue.).

\begin{tabular}{|c|c|c|c|c|c|c|c|c|}
\hline Rank & Sources & TP & PR (\%) & H-Index & g-Index & TC & CPP & PY_Start \\
\hline 1 & International Journal of Climatology & 261 & 3.15 & 54 & 99 & 11,244 & 43.08 & 1989 \\
\hline 2 & Remote Sensing & 240 & 2.89 & 28 & 41 & 2840 & 11.83 & 2010 \\
\hline 3 & Theoretical and Applied Climatology & 200 & 2.41 & 31 & 51 & 3601 & 18.01 & 1987 \\
\hline 4 & Journal of Hydrology & 195 & 2.35 & 49 & 79 & 7519 & 38.56 & 1998 \\
\hline 5 & Water (Switzerland) & 171 & 2.06 & 18 & 26 & 1389 & 8.12 & 2011 \\
\hline 6 & Science of The Total Environment & 140 & 1.69 & 29 & 46 & 2829 & 20.21 & 2008 \\
\hline 7 & Agricultural and Forest Meteorology & 130 & 1.57 & 43 & 69 & 5398 & 41.52 & 1988 \\
\hline 8 & Natural Hazards & 129 & 1.56 & 29 & 51 & 3125 & 24.22 & 2003 \\
\hline 9 & Water Resources Management & 120 & 1.45 & 36 & 70 & 5360 & 44.67 & 1999 \\
\hline 10 & Remote Sensing of Environment & 118 & 1.42 & 54 & 90 & 8399 & 71.18 & 1987 \\
\hline 11 & International Journal of Remote Sensing & 117 & 1.41 & 33 & 64 & 4568 & 39.04 & 1986 \\
\hline 12 & $\begin{array}{l}\text { International Geoscience and Remote } \\
\text { Sensing Symposium (IGARSS) }\end{array}$ & 101 & 1.22 & 8 & 13 & 289 & 2.86 & 1993 \\
\hline 13 & $\begin{array}{l}\text { Proceedings of SPIE-The International } \\
\text { Society for Optical Engineering }\end{array}$ & 101 & 1.22 & 5 & 6 & 133 & 1.32 & 1990 \\
\hline 14 & Journal of Climate & 99 & 1.19 & 45 & 98 & 12,114 & 122.36 & 1993 \\
\hline 15 & Hydrology and Earth System Sciences & 91 & 1.10 & 34 & 56 & 3350 & 36.81 & 1998 \\
\hline 16 & Agricultural Water Management & 89 & 1.07 & 25 & 41 & 1963 & 22.06 & 1996 \\
\hline 17 & $\begin{array}{l}\text { IOP Conference Series: Earth and } \\
\text { Environmental Science }\end{array}$ & 87 & 1.05 & 7 & 8 & 133 & 1.53 & 2014 \\
\hline 18 & Geophysical Research Letters & 84 & 1.01 & 38 & 76 & 5849 & 69.63 & 1998 \\
\hline 19 & Climate Dynamics & 79 & 0.95 & 33 & 53 & 2950 & 37.34 & 1992 \\
\hline 20 & Environmental Research Letters & 79 & 0.95 & 25 & 43 & 1979 & 25.05 & 2007 \\
\hline
\end{tabular}

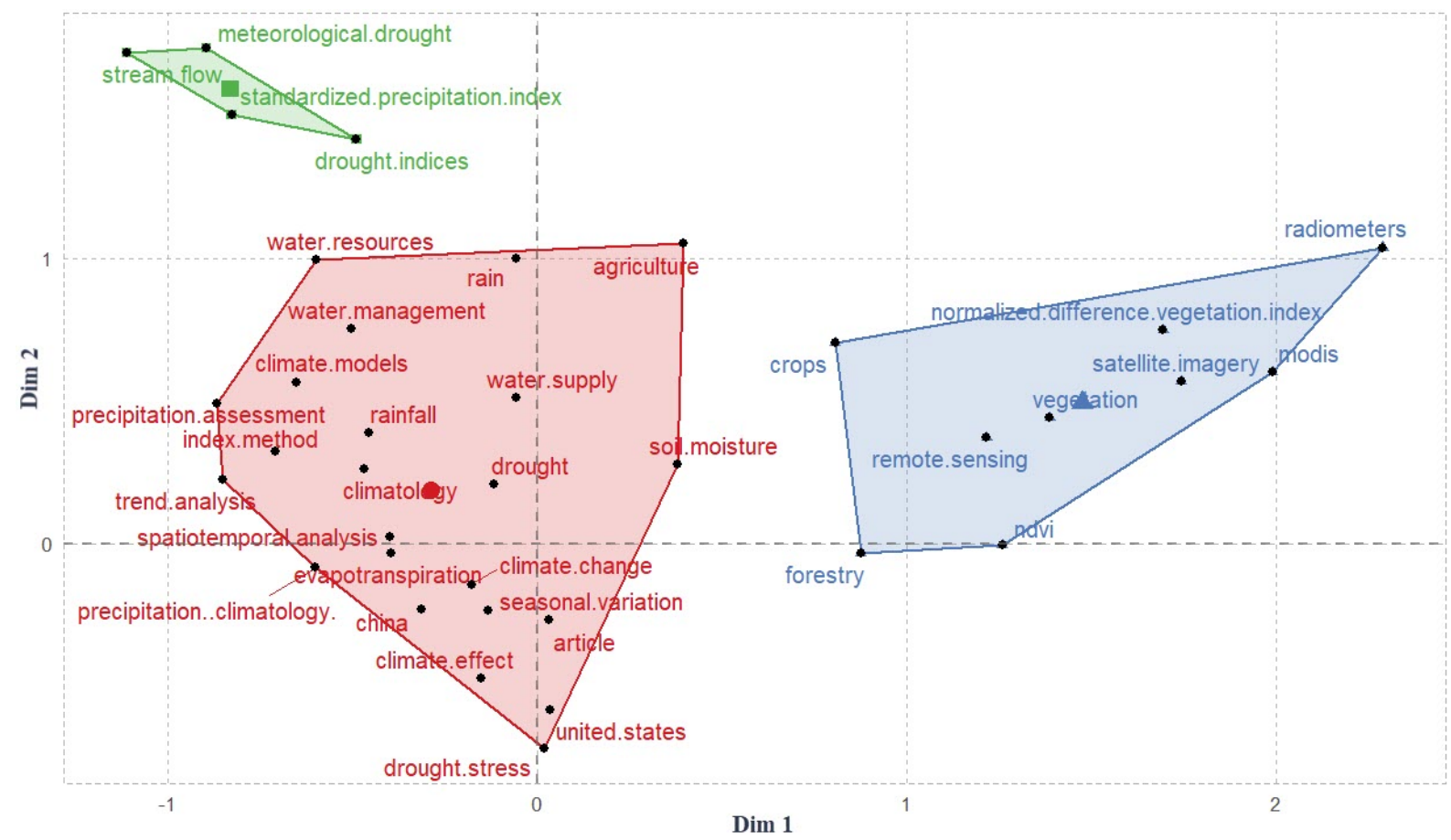

Figure 7. Conceptual structure map of keywords plus in DI studies. 
There are several science- or citation-based mapping methods, such as direct citation, bibliographic coupling, co-citation clustering, and co-citation analysis. These methods differ from each other, and the details of their relative accuracy can be found in [49]. Moreover, there are different methods to evaluate citation relations of scientific studies. For example, Šubelj et al. [50] compared different representative methods such as Louvain (modularity optimization method), Walktrap (random walks-dynamical process), and Infomap (map equation algorithms). The modularity optimization method (Louvain) was reported to be the fastest clustering algorithm by Subelj et al. [50]. Citation analysis is the most common analysis in bibliometrics, and many studies have been used in different fields for author co-citation analysis [51-54]. Therefore, in our study, author co-citation analysis was done with the Louvain clustering algorithm. Co-citation of two documents occurred when two documents were cited together in a third document. Figure 8 presents the findings of frequently cited authors in terms of co-citation. It should be noted that only the first author's name was considered in the analysis. We can interpret the ranking of co-citation analysis in terms of three different algorithms, which are betweenness centrality, closeness centrality, and PageRank (not shown in here). PageRank is one of the complementary methods in citation analysis, which allows us to identify publications referenced by highly cited articles [55]. Betweenness centrality measures the number of times an author acts as a bridge or the shortest path between two other authors [56], whereas closeness centrality measures the distance of a vertex to all others in the network [55,57]. Wang, Zhan, Mckee, Vicente-Serrano, and Li were found to be the top-ranking authors based on betweenness centrality. The closeness centrality outcome showed that the top 5 authors were Wang, Zhan, Li, Liu, and Chen. According to the PageRank algorithm, Mckee, Vicente-Serrano, Palmer, Dai, and Mishra were the top five authors who were referenced by highly cited publications.

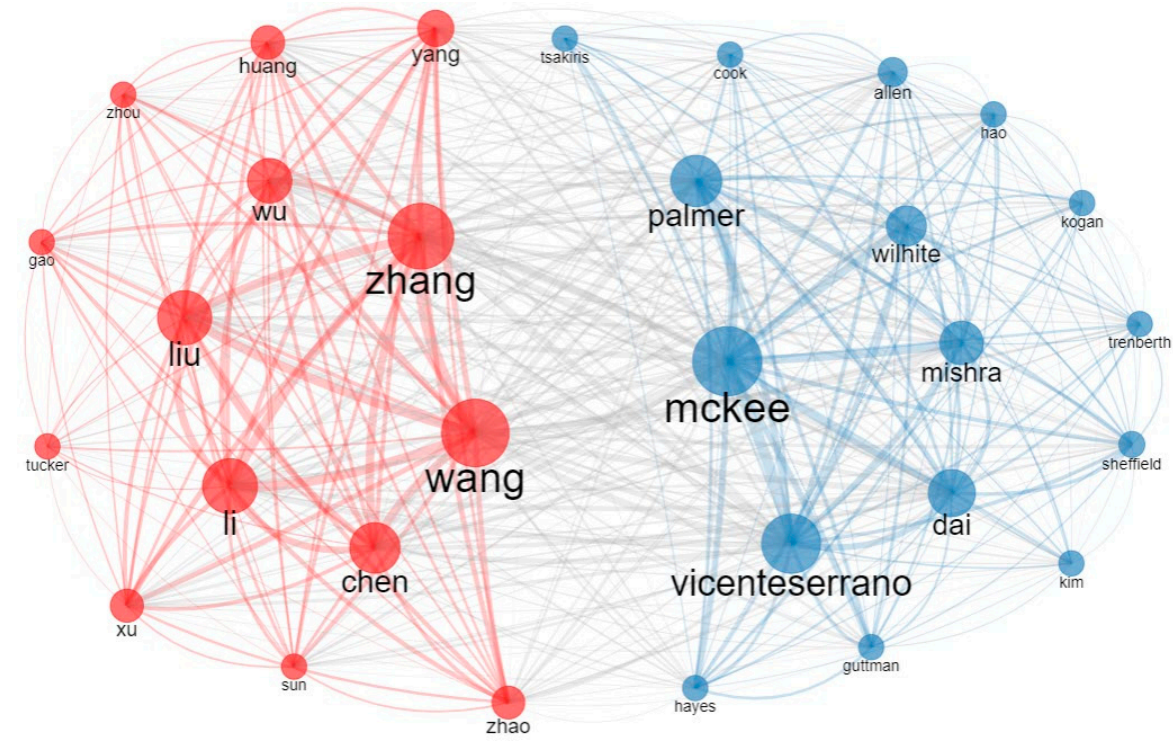

Figure 8. Visualization of author co-citation network in DI studies.

Table 3 summarizes the top 20 DIs and the most applied countries. The top 15 countries were selected based on a higher number of publications, citations, and affiliations in the DI studies, whereas the DIs were selected based on the number of publications and frequency of use by countries. Countries are listed in alphabetical order. DIs were categorized as meteorological, soil moisture (agricultural), hydrological, remote sensing, and composite (or modeled). Then, the DIs were listed in alphabetical order in each category. 
Table 3. Top 20 DIs used in different countries and the number of publications in each country.

\begin{tabular}{|c|c|c|c|c|c|c|c|c|c|c|c|c|c|c|c|c|}
\hline Type & Index & Australia & Brazil & Canada & China & Germany & India & Iran & Italy & Korea & Portugal & $\begin{array}{l}\text { South } \\
\text { Africa }\end{array}$ & Spain & Turkey & $\begin{array}{l}\text { United } \\
\text { Kingdom }\end{array}$ & USA \\
\hline \multirow{8}{*}{ M } & $\mathrm{AI}$ & 7 & 3 & 2 & 51 & 12 & 10 & 13 & 6 & 2 & 2 & 4 & 6 & 3 & 1 & 13 \\
\hline & DRI & 7 & 2 & - & 27 & 6 & 16 & 33 & 7 & 7 & 4 & 4 & 20 & 7 & 7 & 11 \\
\hline & EDI & 4 & - & 2 & 11 & 3 & 9 & 13 & 2 & 24 & 1 & 4 & - & 2 & - & 1 \\
\hline & PDSI & 11 & 5 & 32 & 308 & 26 & 16 & 14 & 7 & 17 & 5 & 5 & 13 & 12 & 21 & 448 \\
\hline & RAI & 25 & 22 & - & 36 & 8 & 25 & 5 & 3 & 2 & - & 5 & 6 & 5 & 7 & 49 \\
\hline & sc-PDSI & 1 & - & 2 & 54 & 7 & - & 1 & 3 & - & - & 2 & 1 & 4 & 3 & 16 \\
\hline & SPEI & 19 & 7 & 19 & 430 & 34 & 44 & 31 & 21 & 32 & 23 & 24 & 88 & 13 & 8 & 86 \\
\hline & SPI & 49 & 46 & 33 & 407 & 45 & 175 & 200 & 88 & 92 & 41 & 41 & 72 & 71 & 37 & 214 \\
\hline \multirow{2}{*}{ SM } & SMA & 5 & 3 & 5 & 23 & 2 & 2 & 7 & 7 & 2 & - & - & 2 & - & 4 & 30 \\
\hline & SWS & 30 & 17 & 5 & 137 & 33 & 23 & 12 & 10 & 2 & 8 & 7 & 63 & 4 & 12 & 81 \\
\hline \multirow{2}{*}{$\mathrm{H}$} & SSFI & - & 3 & - & 30 & 2 & 5 & 3 & 1 & 1 & - & 1 & 5 & 3 & 3 & 8 \\
\hline & SDI & 5 & 2 & 1 & 21 & - & 8 & 25 & 6 & 8 & 1 & 1 & 10 & 3 & 2 & 18 \\
\hline \multirow{7}{*}{ RS } & EVI & 8 & 16 & 6 & 72 & 8 & 3 & 3 & 3 & 1 & - & 3 & 8 & - & 7 & 63 \\
\hline & ESI & 5 & 2 & - & 15 & 3 & 3 & 2 & 4 & 10 & 1 & - & 3 & 1 & 1 & 22 \\
\hline & NDVI & 48 & 24 & 35 & 399 & 50 & 116 & 46 & 48 & 28 & 22 & 28 & 56 & 16 & 24 & 357 \\
\hline & NDWI & 2 & 6 & 5 & 31 & 4 & 14 & 4 & 5 & 6 & 2 & 7 & 1 & - & 4 & 24 \\
\hline & TCI & - & - & - & 55 & 1 & 22 & 6 & 2 & 3 & 7 & 2 & - & 1 & - & 12 \\
\hline & VCI & 2 & 3 & 2 & 62 & 6 & 42 & 9 & 2 & 3 & 6 & 8 & - & 2 & 1 & 26 \\
\hline & VHI & 2 & 5 & - & 38 & 1 & 16 & 2 & 2 & 8 & 4 & 1 & - & 2 & - & 19 \\
\hline CM & GLDAS & 5 & 4 & 1 & 46 & 2 & 4 & 4 & 2 & 5 & - & 1 & - & 2 & 1 & 12 \\
\hline
\end{tabular}

M: meteorological, SM: soil moisture, H: hydrological, RS: remote sensing, CM: composite or modeled. Highlighted cells present the maximum for the related indicator.

Table 3 presents that the USA and China are the two leading countries in the category of DI publications, whereas China is number one in terms of the use of various DIs. The Effective Drought Index (EDI) was the most used drought index in Korea, among other countries, which is the origin of the EDI. The Drought Reconnaissance Index (DRI) and SDI were the most applied indices in Iran compared to other countries.

\subsection{Drought Risk and Forecast}

The word cloud of frequently occurring keywords plus in the DR_DF studies is shown in Figure 9. The most appeared keywords plus were drought $(n=1739)$, risk assessment ( $n=501)$, climate change $(n=461)$, weather forecasting $(n=291)$, forecasting $(n=261)$, China $(n=190)$, prediction $(n=160)$, soil moisture $(n=160)$, and United States $(n=154)$ in the DR_DF studies.

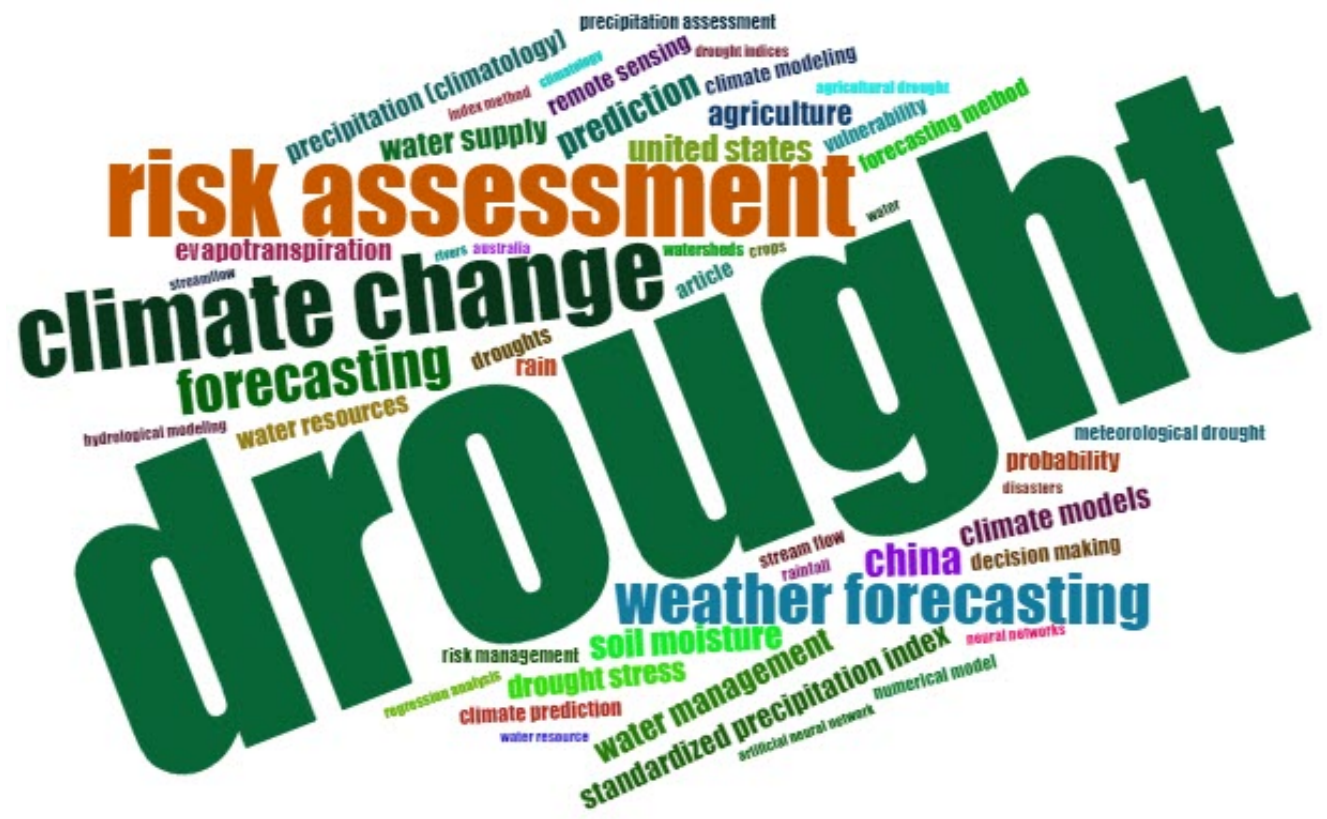

Figure 9. Word cloud for 1694 merged DR_DF publications in terms of keywords plus.

Figures 10 and 11 present the spatial distribution of the top countries in terms of the total number of publications and the SCP and MCP for the DR and DF studies, respectively. 
China was the most dominant country in the DR field in terms of total publications ( $n=175)$, SCP $(n=139)$, and MCP $(n=36)$, which had double the figure of the USA records. The USA $(n=86)$, Australia $(n=31)$, Germany $(n=27)$, and the United Kingdom $(n=25)$ followed China in the DR field. On the other hand, the USA was in the first rank with 192 publications and 152 SCPs, whereas China was leading in the international collaboration level with 50 MCPs on DF studies.

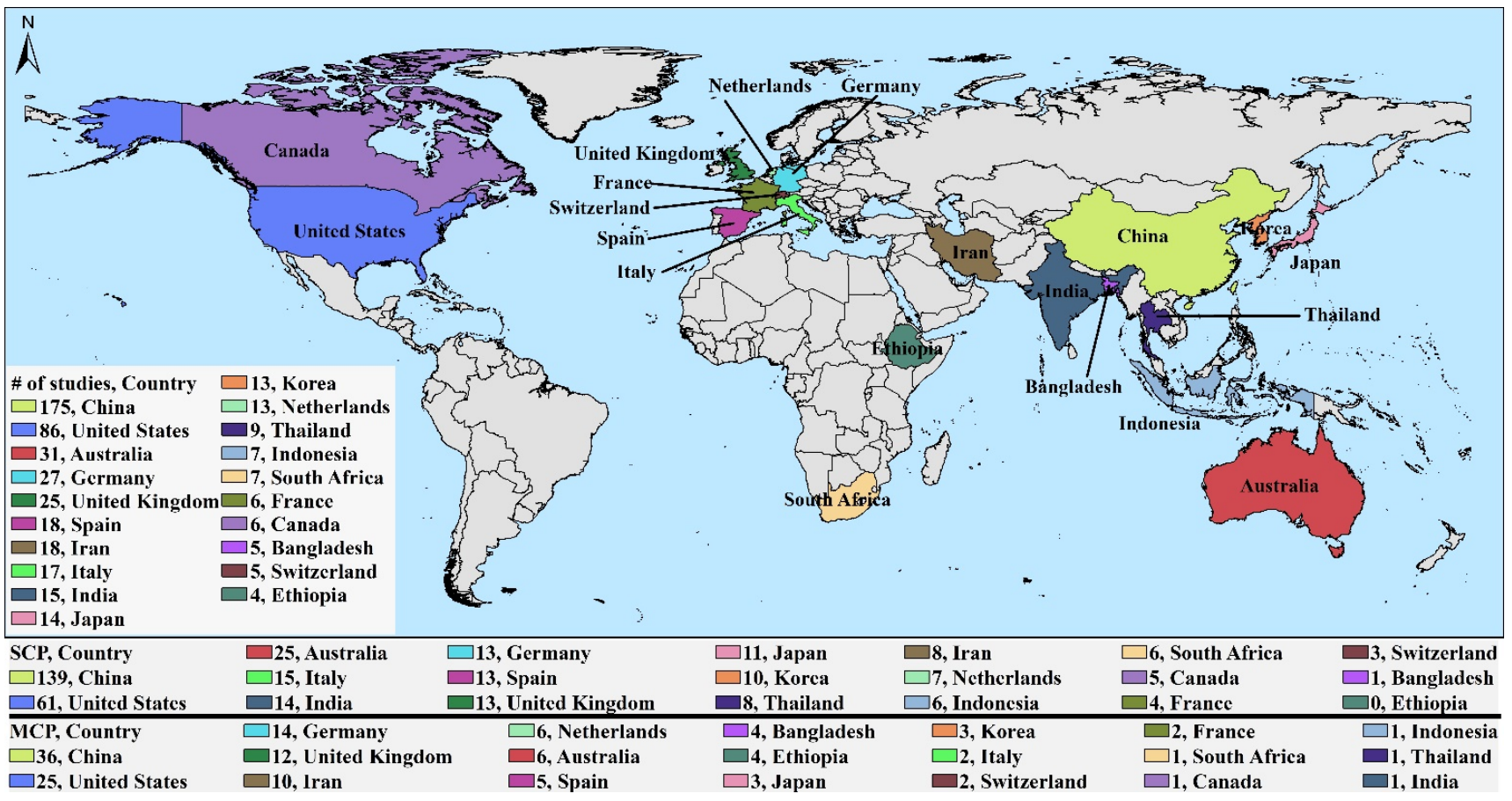

Figure 10. Geographical distribution of the top 20 countries based on the number of publications, $\mathrm{SCP}$, and MCP on DR.

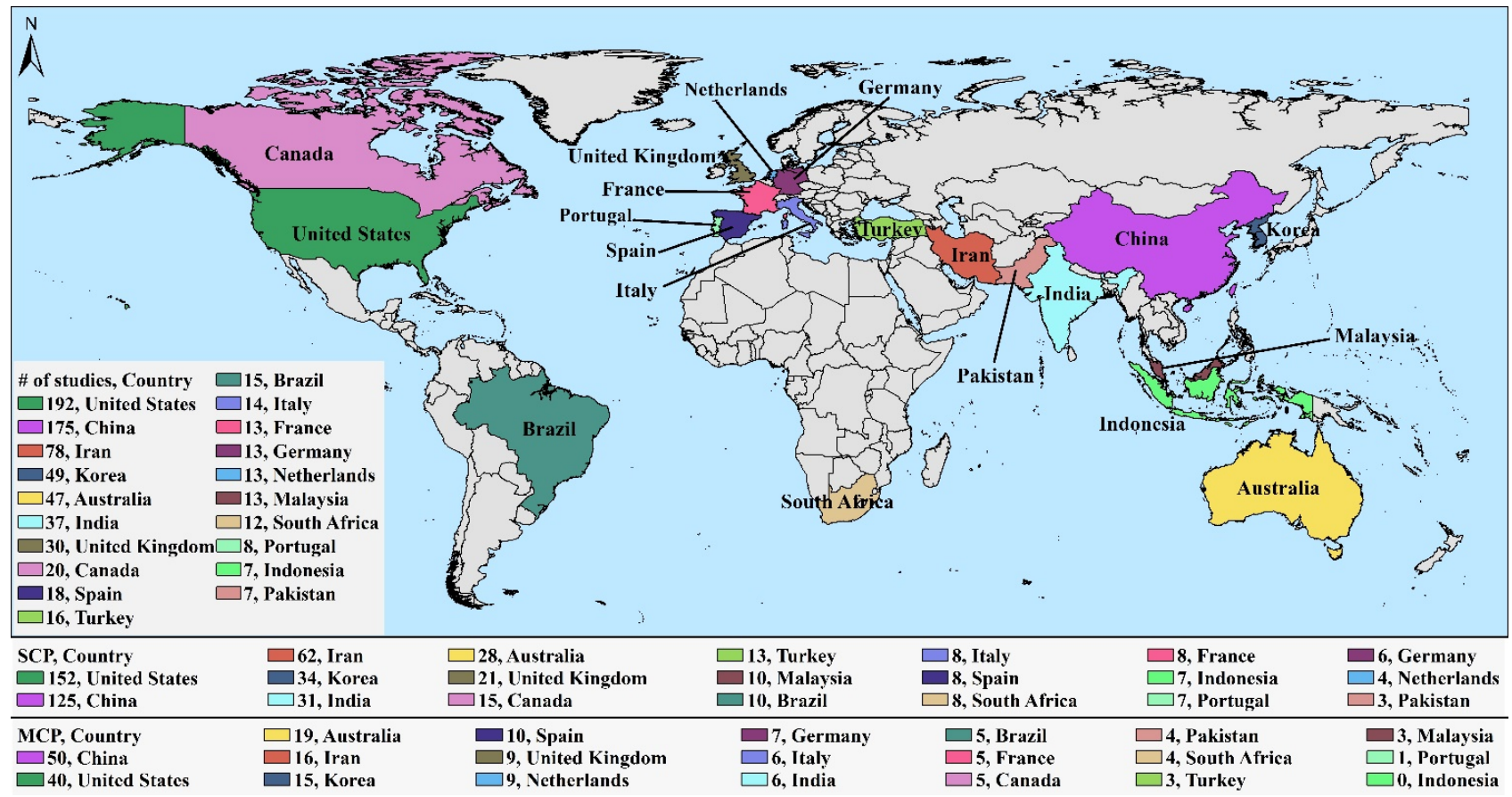

Figure 11. Geographical distribution of top 20 countries based on the number of publications, SCP, and MCP on DF. 
Greece and Mexico were not in the top 20 rankings in the DR and DF studies; however, they were in the 18th and 19th places in the DI studies. Similarly, Brazil, Portugal, and Turkey were not on the top-ranking list for DR, but they had adequate publications in the DI and DF field. South Africa was the only African country that ranked in the top 20 in the DI, DR, and DF studies.

Table 4 shows the ranking of the top 20 countries' total and average article citations in the DR and DF studies. The highest total citation was recorded in the USA, whereas China was the second in both fields. On the other hand, the average article citation of China was lower than most of the countries in the top-ranking list. Some other countries, such as Egypt, Slovakia, and Finland, can be seen in Table 4, yet they were not in the ranking of the top 20 in terms of the number of publications. Australia and United Kingdom showed better performance in the DR and DF fields than in the DI field. For instance, Australia was ranked in the third and fifth places based on the number of publications, and its position was fourth and third in the DR and DF fields, respectively. Moreover, the number of MCPs shows that Australia and the United Kingdom had good inter-country collaboration, followed by the USA and China.

Table 4. Total citations per country in DR and DF studies.

\begin{tabular}{|c|c|c|c|c|c|c|c|}
\hline \multirow{2}{*}{ Rank } & \multicolumn{3}{|c|}{ Drought Risk (DR) } & \multirow{2}{*}{ Rank } & \multicolumn{3}{|c|}{ Drought Forecast (DF) } \\
\hline & Country & $\mathrm{TC}$ & AAC & & Country & $\mathrm{TC}$ & $\mathbf{A A C}$ \\
\hline 1 & USA & 7526 & 87.51 & 1 & USA & 5354 & 27.89 \\
\hline 2 & China & 2128 & 12.16 & 2 & China & 2100 & 12.00 \\
\hline 3 & Germany & 1087 & 40.26 & 3 & Australia & 1566 & 33.32 \\
\hline 4 & Australia & 815 & 26.29 & 4 & United Kingdom & 1528 & 50.93 \\
\hline 5 & United Kingdom & 542 & 21.68 & 5 & Iran & 1259 & 16.14 \\
\hline 6 & Japan & 455 & 32.50 & 6 & India & 982 & 26.54 \\
\hline 7 & Italy & 440 & 25.88 & 7 & Italy & 727 & 51.93 \\
\hline 8 & Netherlands & 278 & 21.38 & 8 & Canada & 643 & 32.15 \\
\hline 9 & Spain & 258 & 14.33 & 9 & France & 464 & 35.69 \\
\hline 10 & India & 172 & 11.47 & 10 & Spain & 453 & 25.17 \\
\hline 11 & Korea & 140 & 10.77 & 11 & Korea & 404 & 8.24 \\
\hline 12 & France & 113 & 18.83 & 12 & Turkey & 341 & 21.31 \\
\hline 13 & Canada & 100 & 16.67 & 13 & Portugal & 335 & 41.88 \\
\hline 14 & Ethiopia & 90 & 22.50 & 14 & Brazil & 314 & 20.93 \\
\hline 15 & South Africa & 86 & 12.29 & 15 & Switzerland & 310 & 62.00 \\
\hline 16 & Iran & 81 & 4.50 & 16 & Japan & 260 & 52.00 \\
\hline 17 & Egypt & 77 & 38.50 & 17 & Germany & 241 & 18.54 \\
\hline 18 & Switzerland & 71 & 14.20 & 18 & Finland & 143 & 47.67 \\
\hline 19 & Slovakia & 70 & 70.00 & 19 & Malaysia & 138 & 10.62 \\
\hline 20 & Greece & 69 & 23.00 & 20 & Netherlands & 138 & 10.62 \\
\hline
\end{tabular}

TC presents total citations; AAC presents average article citations.

Figures 12 and 13 display international collaborations between countries with the selected minimum productivity of publications and citations. Co-authorship analysis for a scientific collaboration has been used in several studies [58-61]. Network visualization maps illustrate the extent and strength link among countries. The size of the circles depicts the total strength of the country, and the thickness of the lines represents the strength of collaboration between any two countries. 


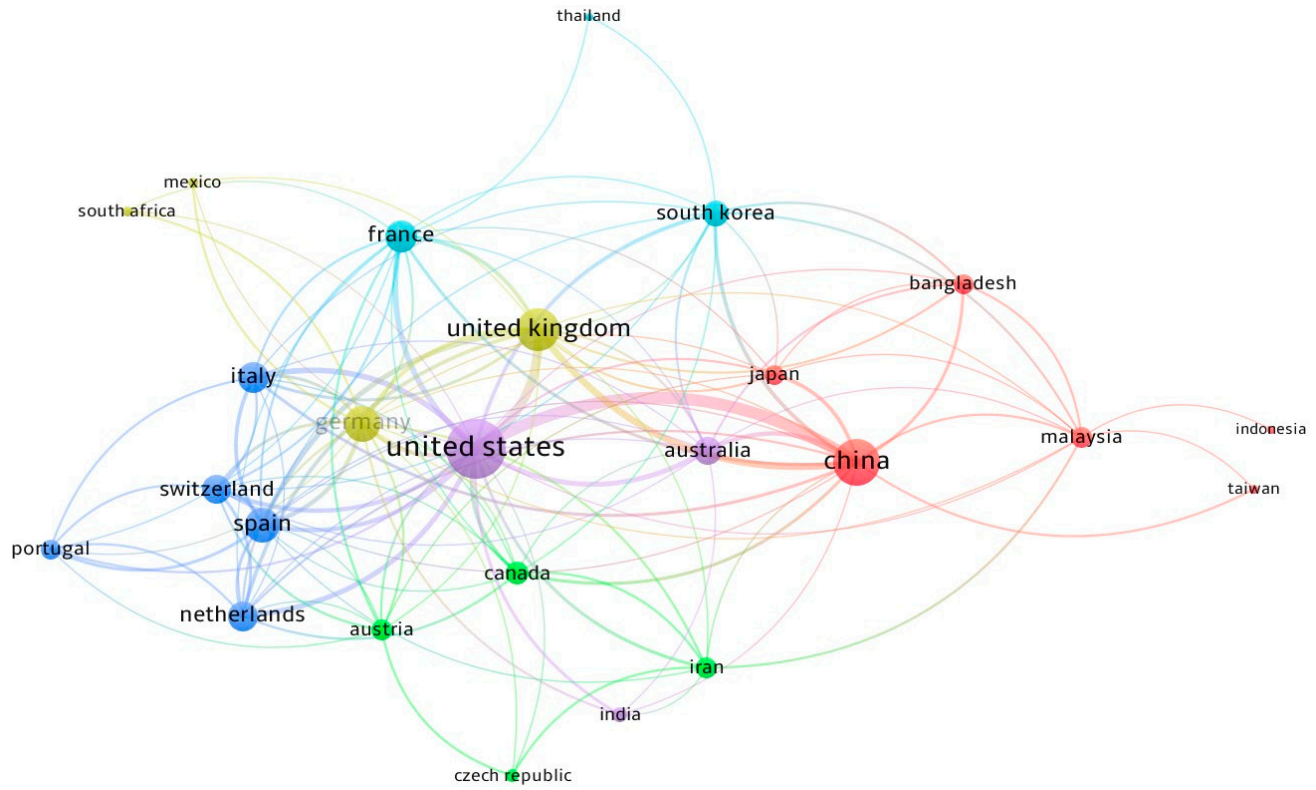

Figure 12. Network visualization map of country co-authorships in the DR field. Countries with a minimum of 10 published and cited articles were included. The map includes 25 out of 90 countries in 6 clusters. Total link strength of the top 5 countries are as follows: USA $=100$, China $=65$, United Kingdom $=55$, Germany $=40$, Spain $=37$.

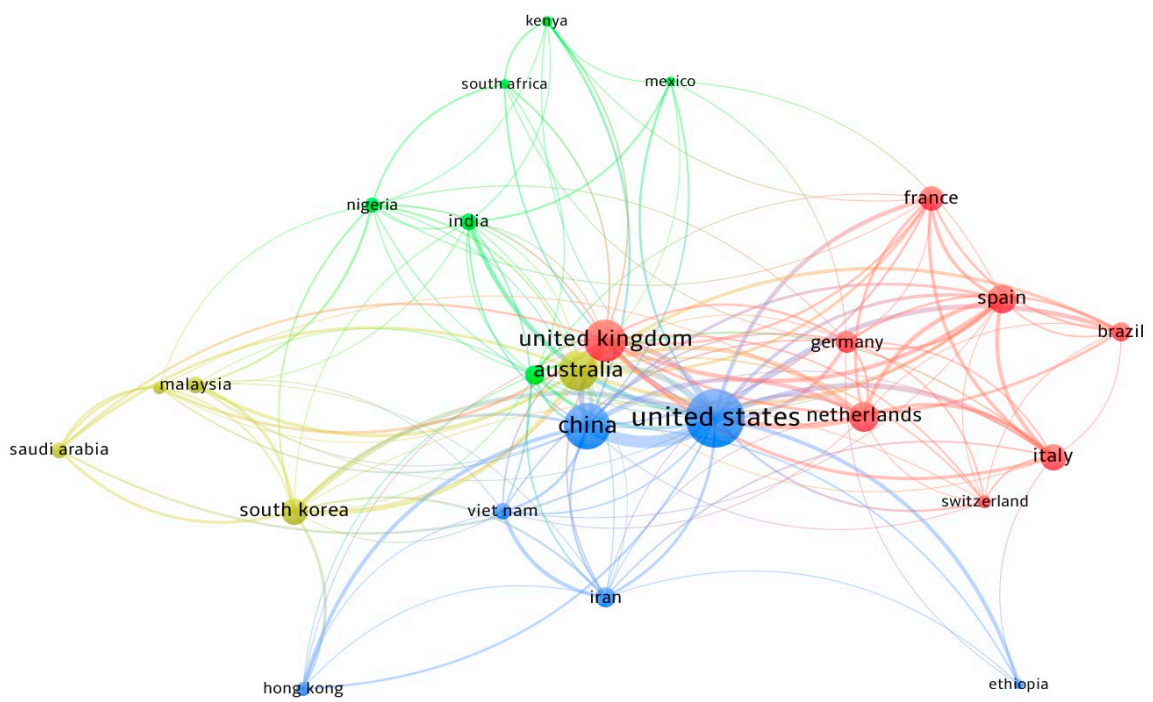

Figure 13. Network visualization map of country co-authorships in the DF field. Countries with a minimum of 10 published and cited articles were included. The map includes 25 countries in 4 clusters. Total link strength of the top 5 countries are as follows: USA $=137$, China $=97$, United Kingdom $=83$, Australia $=76$, Netherlands $=52$.

Co-authorship analysis between countries with the full counting method [21] shows that there were 124 links between 25 out of 90 countries in 6 clusters in the DR field (Figure 12). The following pairs of countries were found to be having strong collaborations: USA-China (link strength = 20), USA-UK (link strength =14), China-UK (link strength = 9), USA-Italy, and USA-France (link strength $=7$ ). Number of co-authorships was the highest for the USA, followed by China and the UK, based on the DR studies.

Figure 13 depicts 153 links between 25 out of 98 countries in 4 clusters in the DF field. The strong collaborations were found among the following countries: USA-China (link strength $=29$ ), USA-Australia (link strength $=10$ ), UK-Netherlands (link strength $=10$ ), 
USA-UK (link strength =9), USA-Italy, and China-UK (link strength $=9$ ). The number of co-authorships was the highest for the USA, followed by China and the UK, based on the DF studies.

Figure 14 presents the most relevant sources for the DR_DF studies. Results from the study disclosed the top 20 sources with the most published research articles on DR_DFrelated research. Natural Hazards was ranked first, with 56 articles, $19 \mathrm{H}$-index, and 1258 total citations. The Journal of Hydrology was ranked second, with 45 articles, 23 H-index (the highest), and 1801 total citations, followed by Theoretical and Applied Climatology (38 articles, $16 \mathrm{H}$-index, 539 total citations). The Journal of Hydrology had the highest citations (1801 total citations), followed by the Journal of Hydrometeorology, with 1399 total citations.

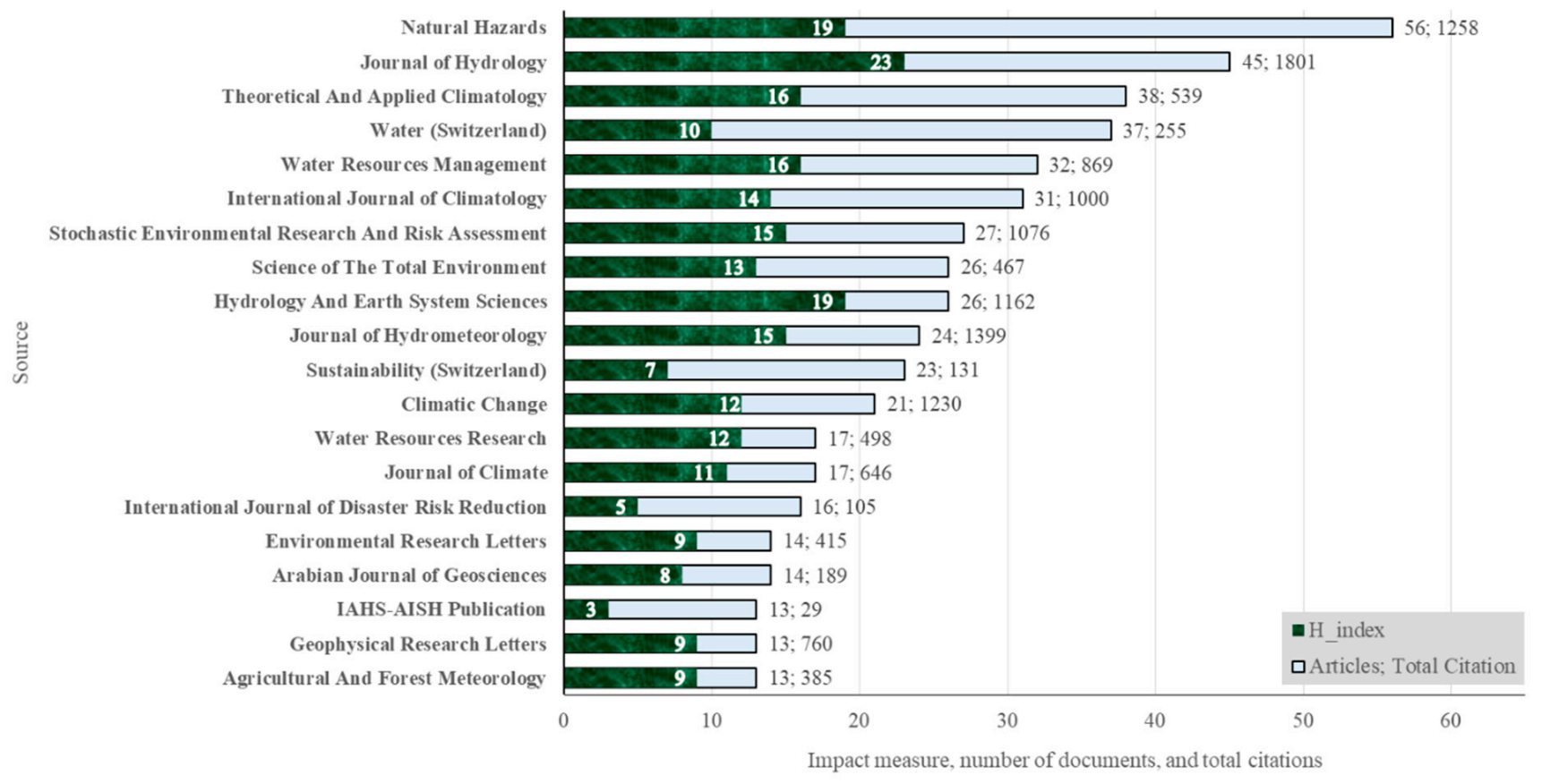

Figure 14. Most relevant sources in the DR_DF field.

Trend topics (TTs) on DR_DF research between 1990 and June 2021 are shown in Figure 15. TTs were created based on the most frequent keywords plus, similar to the word cloud (Figure 9). However, TTs reveal the most frequent words with their occurrence by time. The size of the dots represents the frequency of words, whereas the horizontal line depicts the time frame of frequency of occurrence. For instance, the term 'New South Wales' occurred 16 times between 2019 and 2021 (June included). Why had 'New South Wales' been in the TTs for the last 2 years? This was because New South Wales (NSW) has had exceptional droughts since mid-2017 [62-64] and extraordinary wildfires in 2019/2020 as a cascading effect of drought [65]. Therefore, DR_DF-related studies on the 'New South Wales' term have been trending since 2019. Furthermore, the frequency of the term 'Australia' was recorded 70 times between 2008 and 2019. This result clearly shows that the number of studies on DR_DF in Australia was focused after one of the worst droughts, the 'Millennium Drought' [66,67]. Similarly, other TTs allow researchers to interpret how studies have evolved over time and what trends they show. 


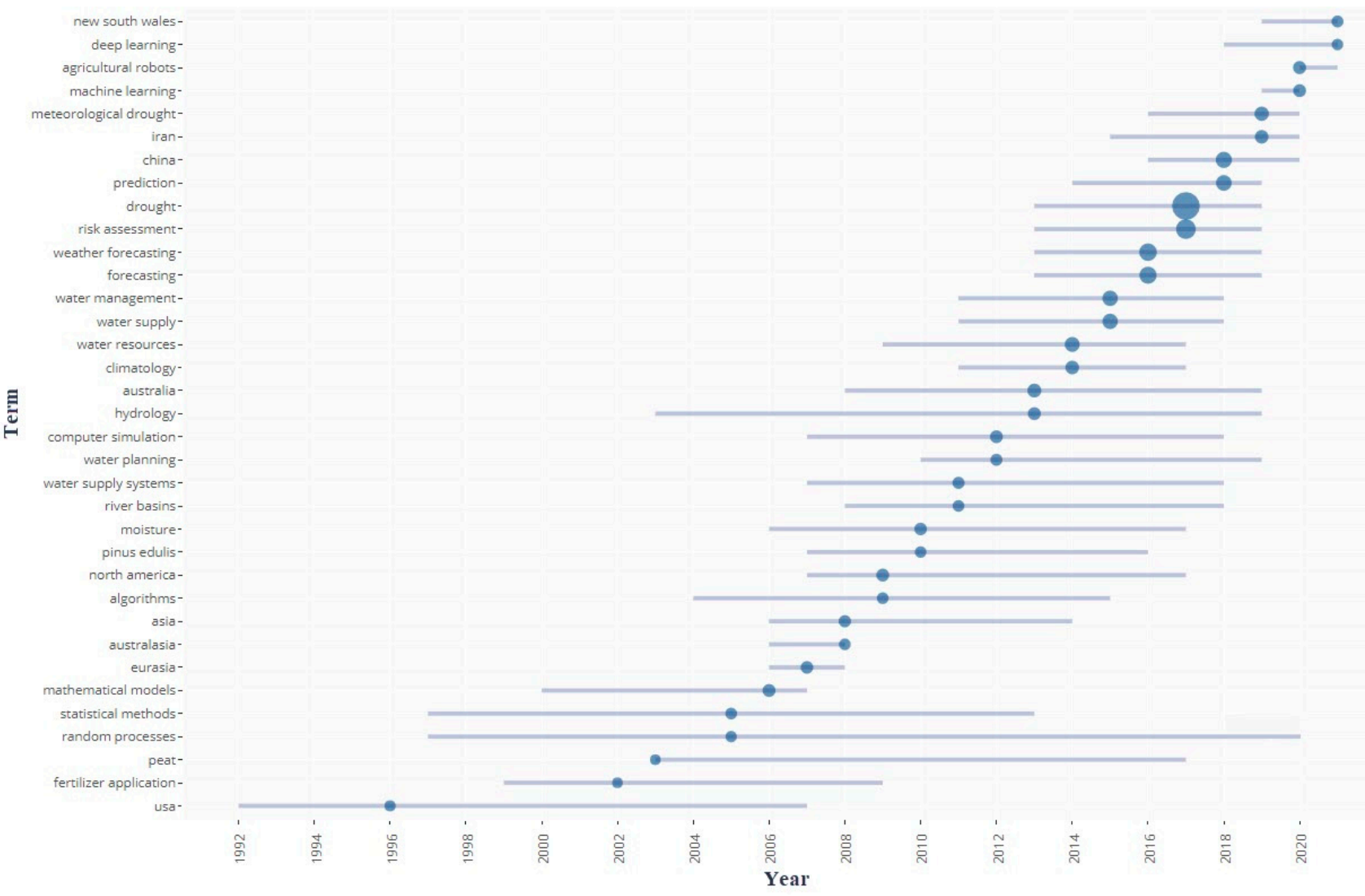

Figure 15. Trend topics on DR_DF-related studies in terms of keywords plus.

We determined research themes that allowed for the superior interpretation of the results. Figure 16 presents thematic maps of author keywords in the DR_DF-related studies. The $x$-axis represents the centrality (relevance degree), which measures the importance of the selected theme, and the $y$-axis represents the density (development degree), which measures the development of the chosen theme [68,69]. The graph was divided into four parts as follows: motor themes (the upper right quadrant), niche themes (the upper left quadrant), emerging or declining themes (the lower left quadrant), and basic themes (the lower right quadrant). Motor themes are well developed and important for the structuring of the research field. The cluster placed in the motor themes shows a strong relevance degree and high density. Niche themes are well developed but isolated and hence are of only marginal importance for the field. Niche themes have high density but lower centrality. Emerging or declining themes are weakly developed and marginal. The lower left quadrant of the thematic map has both low density and low centrality. Basic themes are important for a research field not yet well developed. This theme has high centrality but lower density.

We used the parameters to create the thematic map (Figure 16), as follows: the top 430 keywords; however, the items placed in the clusters are set to the minimum cluster frequency of 3, one representative label for each cluster. Other relevant details about cluster representation, themes, and keywords in clusters are given in Table S2 in the Supplementary section. 


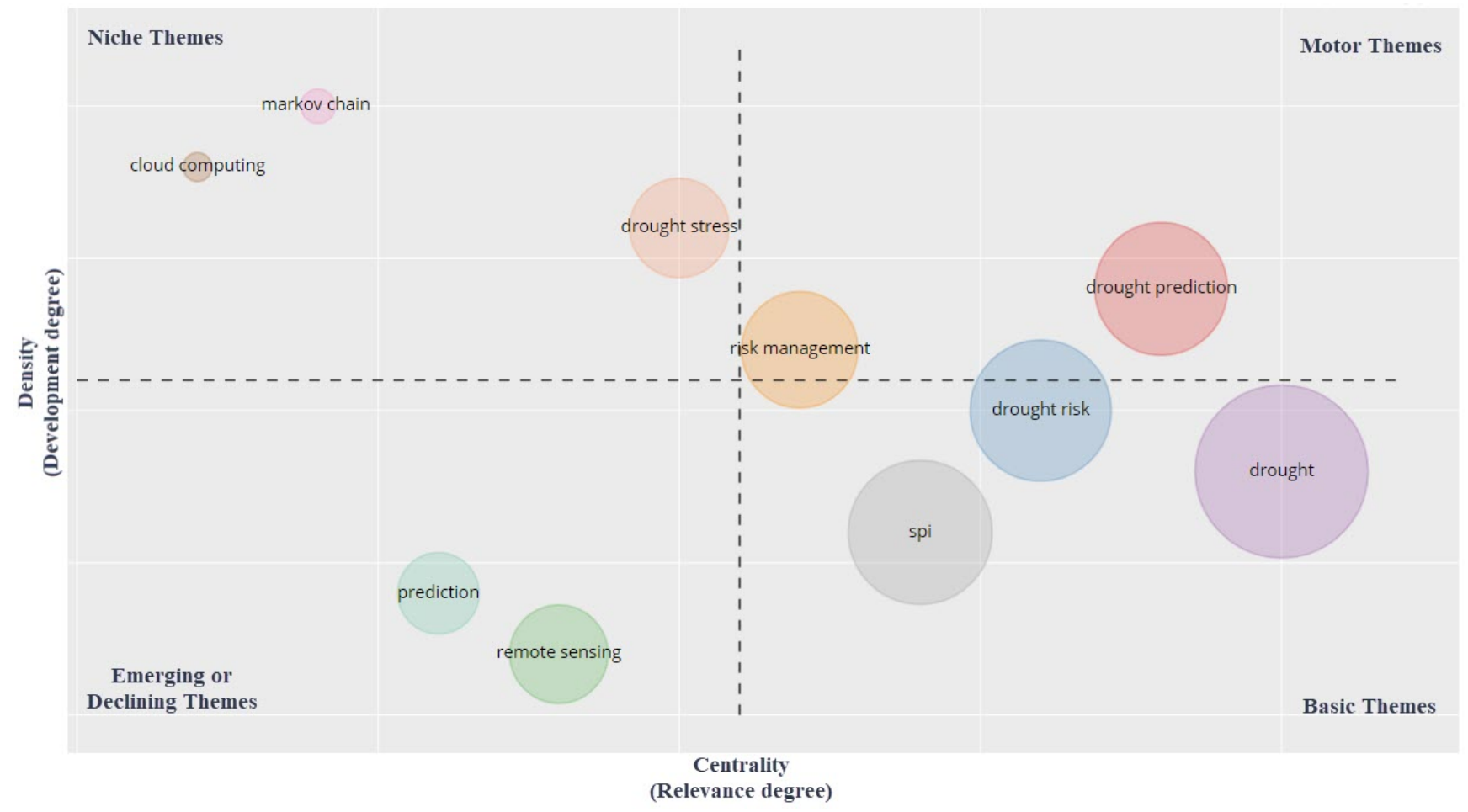

Figure 16. Thematic map.

In total, 10 clusters were generated in the thematic map of keywords. 'Drought', 'drought risk', and 'SPI' clusters were placed in basic themes, and the topics under these clusters were related to climate change, risk assessment, agricultural drought, drought forecasting, and vulnerability. Some part of the 'drought risk' theme was in motor themes, and many parts were in the basic theme. The clusters placed in the basic or transversal theme were important for research; however, more research is required. 'Risk management' and 'drought prediction' clusters were positioned in motor themes. 'Drought prediction' showed higher centrality and density than 'risk management'. Some topics under these clusters were related to hydrological drought, climate variability, water management, uncertainty, and meteorological drought. It may be noted that more research is needed in the 'risk management' category, with water management, drought management, and climate variability topics. 'Drought stress', 'cloud computing', and 'Markov chain' were placed in the niche theme. These clusters (or themes) were considered highly developed but isolated. The density of 'cloud computing' and 'Markov chain' was high, yet centrality was low. 'Drought stress', on the other hand, had higher centrality/lower density than 'cloud computing' and 'Markov chain'. Drought tolerance, water deficit, grain yield, and wheat were related to the 'drought stress' theme. Emerging or declining themes involved 'prediction' and 'remote sensing' clusters. These two marginal themes had low density and low centrality, and they were weakly developed. Some topics under these clusters were modeling, land surface model, GIS, and downscaling which indicate that more research is required in this field [20].

Table 5 presents the top- 20 most productive authors on DR- and DF-related studies. The number of an academic researcher's output can reveal the strength of their research and their effectiveness in carrying out an adequate academic study [17]. Hence, to weigh an author's impact on a particular field, the quantity of a researcher's academic papers in a field can be inferred as an important index. The results showed that the top authors were from China, especially based on DR-related studies. The most productive author in the DR field was Zhang Q, who had 20 articles. 4.31 article fractionalized, and $11 \mathrm{H}$-index. Wilhite DA, from the USA, had the highest total number of citations in this field: he published 
9 articles in the field and was cited 448 times. Singh VP, from the USA, was the most productive author in the area of DF with 15 articles, 700 total citations, and $12 \mathrm{H}$-index.

Table 5. Most productive authors on drought risk and drought forecast studies.

\begin{tabular}{|c|c|c|c|c|c|c|c|c|c|c|}
\hline \multirow{2}{*}{ Rank } & \multicolumn{5}{|c|}{ Drought Risk (DR) } & \multicolumn{5}{|c|}{ Drought Forecast (DF) } \\
\hline & Authors & Articles & AF & H-Index & TC & Authors & Articles & AF & H-Index & TC \\
\hline 1 & Zhang Q & 20 & 4.41 & 11 & 398 & Singh VP & 15 & 4.00 & 12 & 700 \\
\hline 2 & Wang J & 19 & 4.13 & 9 & 238 & Wang Y & 15 & 3.04 & 7 & 174 \\
\hline 3 & Wang Y & 19 & 3.32 & 4 & 166 & Kim TW & 13 & 3.84 & 6 & 385 \\
\hline 4 & Zhang J & 15 & 4.18 & 8 & 277 & Yuan X & 11 & 3.43 & 8 & 563 \\
\hline 5 & Zhang L & 13 & 2.78 & 6 & 194 & Chen J & 11 & 2.92 & 5 & 107 \\
\hline 6 & Chen J & 11 & 3.43 & 5 & 141 & Wood EF & 10 & 2.90 & 9 & 662 \\
\hline 7 & $\operatorname{Liu} X$ & 10 & 2.09 & 5 & 91 & Hao Z & 10 & 2.06 & 7 & 481 \\
\hline 8 & Wilhite DA & 9 & 5.67 & 7 & 448 & Svoboda M & 10 & 1.30 & 8 & 316 \\
\hline 9 & Zhang Y & 9 & 1.74 & 4 & 108 & Deo RC & 9 & 2.67 & 8 & 565 \\
\hline 10 & Kim TW & 9 & 2.09 & 4 & 87 & Dutra E & 9 & 1.51 & 7 & 410 \\
\hline 11 & Singh VP & 8 & 1.85 & 5 & 196 & Wetterhall F & 9 & 1.72 & 6 & 374 \\
\hline 12 & Zhang X & 8 & 1.45 & 5 & 171 & Wang L & 9 & 2.06 & 4 & 358 \\
\hline 13 & Wang C & 8 & 1.48 & 3 & 60 & Tadesse $\mathrm{T}$ & 9 & 2.21 & 7 & 207 \\
\hline 14 & Li J & 8 & 1.79 & 3 & 47 & Liu Y & 9 & 2.34 & 4 & 72 \\
\hline 15 & Li Y & 7 & 1.36 & 4 & 161 & Kumar A & 8 & 1.73 & 7 & 434 \\
\hline 16 & Wang L & 7 & 1.20 & 5 & 123 & Kisi O & 8 & 1.88 & 4 & 200 \\
\hline 17 & Huang Q & 7 & 1.31 & 4 & 108 & Rhee J & 8 & 2.89 & 4 & 146 \\
\hline 18 & Shaw R & 7 & 3.17 & 5 & 81 & Masinde M & 8 & 4.42 & 4 & 66 \\
\hline 19 & Hayes MJ & 6 & 1.47 & 4 & 68 & Panu US & 8 & 3.67 & 4 & 50 \\
\hline 20 & Baо $Y$ & 6 & 1.29 & 3 & 47 & Lee JH & 8 & 1.93 & 4 & 48 \\
\hline
\end{tabular}

Note: AF and TC refer to article fractionalized and total citations, respectively.

\section{Conclusions}

This study was not intended to identify the frequency and severity of droughts in any country/region but rather to map the trends in research on selected drought aspects by bibliometric analysis. Here, the Scopus database was used in sourcing the relevant articles on DI-, DR- and DF-related studies.

The percentages of documents out of the selected 11,291 publications were found to be $57 \%, 8 \%, 4 \%, 29 \%$, and $2 \%$ based on meteorological, soil moisture, hydrological, remote sensing, and composite or modeled DIs, respectively. The most globally used DIs were found to be SPI, NDVI, PDSI, and SPEI, with 2483, 2023, 1245, and 1207 publications, respectively. The most notable DIs used in each category were SPI (meteorological), SWS (soil moisture), SDI (hydrological), NDVI (remote sensing), and GLDAS (composite/modeled). In terms of the 'ease of use', $55 \%(n=6212), 38 \%(n=4253)$ and $7 \%(n=826)$ of the publications belonged to levels 1, 2, and 3 ease of use, respectively. The DI studies showed an increase after the 1990s, and 35 out of 50 DIs were first published after the 1990s. An abrupt change was detected in 2010 for the SPI-related studies. The results show that there has been strong global interest and growth in the applications and developments of DIs over the past 20 years.

At the country level, the USA and China were found to be the two leading and productive countries in terms of the largest number of publications and the greatest academic influence on the DI studies. Furthermore, China also holds the key leadership position in DI studies in terms of using a variety of the top drought indices, whereas the USA had the most cited academic researchers' publications. It should be noted here that the occurrence of droughts in a given country is not conveyed by this analysis; for example, the US authors co-authored papers on droughts with the authors of other countries, where the focus was not US droughts. 
The most productive journal for the DI field was found to be the International Journal of Climatology in terms of total number of publications $(n=261), \mathrm{H}$-index (54), g-index (99), and publication rate (3.15\%) when compared to 1424 sources in the area of DIs.

Similar to the DI studies, the USA and China were found to be the most productive countries in terms of the quantity and quality of academic outputs in the DR and DF fields. Furthermore, network analysis of country co-authorships highlighted the top 3 countries as the USA, China, and the United Kingdom, in this field. Natural Hazards was found to be the first-ranked journal in terms of the number of published articles; although fewer papers were published in the Journal of Hydrology, it received the highest total citations and H-index. Singh VP is the most prolific author and has the greatest academic influence on the DF field, with the largest number of publications, the highest H-index, and far higher total citations than others, whereas Zhang $Q$ was identified as the most productive author in the DR-related studies. Wilhite DA (from the USA) published fewer papers in the DR field, yet his publications were more widely cited and had a significant influence in the field.

Trend topics analysis based on 'keywords plus' showed how researchers had focused on the area of DR and DF over time. This study also explored the research themes on the DR_DF field and generated a thematic map, which allowed us to interpret the results of the bibliometric analysis in terms of keywords. Ten clusters were placed in four different themes, and their position and frequency allowed us to reveal their importance, development, and relevance in the field. According to the thematic map, more research is needed in risk management, water management, and drought management themes. This review study performed a bibliometric analysis to determine the main themes of scientific progress and the evolution and trends in the area of DI, DR, and DF research, which may help provide guidance for future research in drought science.

Supplementary Materials: The following supporting information can be downloaded at: https: / / www.mdpi.com/article/10.3390/w14020253/s1, Table S2: Drought indices in terms of ease of use, number of publications, most used countries and time span; Table S1: Themes and keywords in thematic map.

Author Contributions: G.Y. designed the research, analyzed the data, and drafted the manuscript; A.R. and V.P.S. helped to evaluate the results and edited the manuscript. All authors have read and agreed to the published version of the manuscript.

Funding: This research received no funding.

Institutional Review Board Statement: Not applicable.

Informed Consent Statement: Not applicable.

Data Availability Statement: The data presented in this study are openly available in the Scopus database (http: / / www.scopus.com) (accessed on 30 June 2021).

Acknowledgments: The authors acknowledge the developers of all the software/tools used in the analysis and two anonymous reviewers whose constructive comments assisted in improving the manuscript significantly.

Conflicts of Interest: The authors declare no conflict of interest.

\section{References}

1. Schwalm, C.R.; Anderegg, W.R.L.; Michalak, A.M.; Fisher, J.B.; Biondi, F.; Koch, G.; Litvak, M.; Ogle, K.; Shaw, J.D.; Wolf, A.; et al. Global patterns of drought recovery. Nature 2017, 548, 202-205. [CrossRef]

2. Herbst, P.; Bredenkamp, D.; Barker, H. A technique for the evaluation of drought from rainfall data. J. Hydrol. 1966, 4, 264-272. [CrossRef]

3. Rahman, A. Social hydrology. In Handbook of Applied Hydrology; Singh, V.P., Ed.; McGraw-Hill: New York, NY, USA, 2017; Chapter 155, pp. 1-10.

4. Wilhite, D.A. Drought as a natural hazard: Concepts and definitions. In Drought: A Global Assessment; Routledge: London, UK, 2000. 
5. Svoboda, M.; LeComte, D.; Hayes, M.; Heim, R.; Gleason, K.; Angel, J.; Rippey, B.; Tinker, R.; Palecki, M.; Stooksbury, D.; et al. The Drought Monitor. Bull. Am. Meteorol. Soc. 2002, 83, 1181-1190. [CrossRef]

6. Yihdego, Y.; Vaheddoost, B.; Al-Weshah, R. Drought indices and indicators revisited. Arab. J. Geosci. 2019, 12, 69. [CrossRef]

7. Wilhite, D.A.; Glantz, M.H. Understanding: The drought phenomenon: The role of definitions. Water Int. 1985, 10, 111-120. [CrossRef]

8. Zargar, A.; Sadiq, R.; Naser, G.; Khan, F.I. A review of drought indices. Environ. Rev. 2011, 19, 333-349. [CrossRef]

9. Wilhite, D.A. Drought and Water Crises: Science, Technology, and Management Issues; CRC Press: Boca Raton, FL, USA, 2005.

10. Wilhite, D.A. Drought Monitoring as a Component of Drought Preparedness Planning. In Coping with Drought Risk in Agriculture and Water Supply Systems; Springer: Berlin/Heidelberg, Germany, 2009; pp. 3-19. [CrossRef]

11. Eslamian, S. Handbook of Engineering Hydrology: Modeling, Climate Change, and Variability; CRC Press: Boca Raton, FL, USA, 2014

12. World Meteorological Organization (WMO); Global Water Partnership (GWP). Handbook of Drought Indicators and Indices; Svoboda, M., Fuchs, B.A., Eds.; Integrated Drought Management Programme (IDMP): Geneva, Switzerland, 2016.

13. Hagenlocher, M. Drought vulnerability and risk assessments: State of the art, persistent gaps, and research agenda. Environ. Res. Lett. 2019, 14, 083002. [CrossRef]

14. Orimoloye, I.R.; Ekundayo, T.C.; Ololade, O.O.; Belle, J.A. Systematic mapping of disaster risk management research and the role of innovative technology. Environ. Sci. Pollut. Res. 2020, 28, 4289-4306. [CrossRef] [PubMed]

15. Orimoloye, I.R.; Belle, J.A.; Olusola, A.O.; Busayo, E.T.; Ololade, O.O. Spatial assessment of drought disasters, vulnerability, severity and water shortages: A potential drought disaster mitigation strategy. Nat. Hazards 2020, 105, 2735-2754. [CrossRef]

16. Kchouk, S.; Melsen, L.A.; Walker, D.W.; Van Oel, P.R. A review of drought indices: Predominance of drivers over impacts and the importance of local context. Nat. Hazards Earth Syst. Sci. Discuss. 2021, in press.

17. Wang, Z.; Zhao, Y.; Wang, B. A bibliometric analysis of climate change adaptation based on massive research literature data. J. Clean. Prod. 2018, 199, 1072-1082. [CrossRef]

18. De Bakker, F.G.; Groenewegen, P.; den Hond, F. A Bibliometric Analysis of 30 Years of Research and Theory on Corporate Social Responsibility and Corporate Social Performance. Bus. Soc. 2005, 44, 283-317. [CrossRef]

19. Aria, M.; Cuccurullo, C. bibliometrix: An R-tool for comprehensive science mapping analysis. J. Informetr. 2017, 11, 959-975. [CrossRef]

20. Mishra, A.K.; Singh, V.P. Drought modelling-A review. J. Hydrol. 2011, 403, 157-175. [CrossRef]

21. Van Eck, N.J.; Waltman, L. Software survey: VOSviewer, a computer program for bibliometric mapping. Scientometrics 2010, 84, 523-538. [CrossRef]

22. Van Eck, N.J.; Waltman, L. CitNetExplorer: A new software tool for analyzing and visualizing citation networks. J. Inf. 2014, 8, 802-823. [CrossRef]

23. Cobo, M.; López-Herrera, A.; Herrera-Viedma, E.; Herrera, F. SciMAT: A new science mapping analysis software tool. J. Am. Soc. Inf. Sci. Technol. 2012, 63, 1609-1630. [CrossRef]

24. Persson, O.; Danell, R.; Schneider, J.W. How to use Bibexcel for various types of bibliometric analysis. In Celebrating Scholarly Communication Studies: A Festschrift for Olle Persson at His 60th Birthday; Omea University: Omea, Sweden, 2009; Volume 5, pp. 9-24.

25. Chen, C.M. CiteSpace II: Detecting and visualizing emerging trends and transient patterns in scientific literature. J. Am. Soc. Inf. Sci. Technol. 2006, 57, 359-377. [CrossRef]

26. Palmer, W.C. Meteorological Drought; Research Paper No. 45; US Department of Commerce, Weather Bureau: Silver Spring, MD, USA, 1965

27. Alley, W.M. The Palmer Drought Severity Index: Limitations and Assumptions. J. Clim. Appl. Meteorol. 1984, 23, 1100-1109. [CrossRef]

28. Soulé, P.T. Spatial patterns of drought frequency and duration in the contiguous USA based on multiple drought event definitions. Int. J. Clim. 1992, 12, 11-24. [CrossRef]

29. Weber, L.; Kkemdirim, L. Palmer's drought indices revisited. Geogr. Ann. Ser. A Phys. Geogr. 1998, 80, 153-172. [CrossRef]

30. Guttman, N.B. Comparing the palmer drought index and the standardized precipitation index. JAWRA J. Am. Water Resour. Assoc. 1998, 34, 113-121. [CrossRef]

31. Mishra, A.K.; Singh, V.P. A review of drought concepts. J. Hydrol. 2010, 391, 202-216. [CrossRef]

32. Hayes, M.J.; Svoboda, M.D.; Wiihite, D.A.; Vanyarkho, O.V. Monitoring the 1996 Drought Using the Standardized Precipitation Index. Bull. Am. Meteorol. Soc. 1999, 80, 429-438. [CrossRef]

33. Vicente-Serrano, S.M.; Beguería, S.; López-Moreno, J.I. A Multiscalar Drought Index Sensitive to Global Warming: The Standardized Precipitation Evapotranspiration Index. J. Clim. 2010, 23, 1696-1718. [CrossRef]

34. Tarpley, J.D.; Schneider, S.R.; Money, R.L. Global Vegetation Indices from the NOAA-7 Meteorological Satellite. J. Clim. Appl. Meteorol. 1984, 23, 491-494. [CrossRef]

35. McKee, T.B.; Doesken, N.J.; Kleist, J. The relationship of drought frequency and duration to time scales. In Proceedings of the 8th Conference on Applied Climatology, Anaheim, CA, USA, 17-22 January 1993; Volume 17, pp. 179-183.

36. Hayes, M.J.; Svoboda, M.; Wall, N.A.; Widhalm, M. The Lincoln Declaration on Drought Indices: Universal Meteorological Drought Index Recommended. Bull. Am. Meteorol. Soc. 2011, 92, 485-488. [CrossRef]

37. Garfield, E. KeyWords Plus-ISI's breakthrough retrieval method. 1. Expanding your searching power on current-contents on diskette. Curr. Contents 1990, 32, 5-9. 
38. Zhang, J.; Yu, Q.; Zheng, F.; Long, C.; Lu, Z.; Duan, Z. Comparing keywords plus of WOS and author keywords: A case study of patient adherence research. J. Assoc. Inf. Sci. Technol. 2015, 67, 967-972. [CrossRef]

39. Mao, N.; Wang, M.-H.; Ho, Y.-S. A Bibliometric Study of the Trend in Articles Related to Risk Assessment Published inScience Citation Index. Hum. Ecol. Risk Assess. Int. J. 2010, 16, 801-824. [CrossRef]

40. Li, J.; Wang, M.-H.; Ho, Y.-S. Trends in research on global climate change: A Science Citation Index Expanded-based analysis. Glob. Planet. Chang. 2011, 77, 13-20. [CrossRef]

41. Hirsch, J.E. An index to quantify an individual's scientific research output. Proc. Natl. Acad. Sci. USA 2005, 102, 16569-16572 [CrossRef]

42. Molinari, J.-F.; Molinari, A. A new methodology for ranking scientific institutions. Scientometrics 2008, 75, 163-174. [CrossRef]

43. Egghe, L. Theory and practise of the g-index. Scientometrics 2006, 69, 131-152. [CrossRef]

44. Costas, R.; Bordons, M. Is g-index better than h-index? An exploratory study at the individual level. Scientometrics 2008, 77, 267-288. [CrossRef]

45. Hirschfeld, H.O. A Connection between Correlation and Contingency. Math. Proc. Camb. Philos. Soc. 1935, 31, 520-524. [CrossRef]

46. Horst, P. Measuring complex attitudes. J. Soc. Psychol. 1935, 6, 369-374. [CrossRef]

47. Fisher, R.A. The Precision of Discriminant Functions. Ann. Eugen. 1940, 10, 422-429. [CrossRef]

48. Cuccurullo, C.; Aria, M.; Sarto, F. Foundations and trends in performance management. A twenty-five years bibliometric analysis in business and public administration domains. Scientometrics 2016, 108, 595-611. [CrossRef]

49. Boyack, K.W.; Klavans, R. Co-citation analysis, bibliographic coupling, and direct citation: Which citation approach represents the research front most accurately? J. Am. Soc. Inf. Sci. Technol. 2010, 61, 2389-2404. [CrossRef]

50. Šubelj, L.; van Eck, N.J.; Waltman, L. Clustering Scientific Publications Based on Citation Relations: A Systematic Comparison of Different Methods. PLoS ONE 2016, 11, e0154404. [CrossRef]

51. White, H.D.; McCain, K.W. Visualizing a discipline: An author co-citation analysis of information science, 1972-1995. J. Am. Soc. Inf. Sci. 1998, 49, 327-355.

52. Andrews, J.E. An author co-citation analysis of medical informatics. J. Med Libr. Assoc. 2003, 91, 47-56.

53. Fang, Y.; Yin, J.; Wu, B. Climate change and tourism: A scientometric analysis using CiteSpace. J. Sustain. Tour. 2017, 26, 108-126. [CrossRef]

54. Kreuzman, H. A co-citation analysis of representative authors in philosophy: Examining the relationship between epistemologists and philosophers of science. Scientometrics 2001, 51, 525-539. [CrossRef]

55. Ding, Y.; Yan, E.; Frazho, A.; Caverlee, J. PageRank for ranking authors in co-citation networks. J. Am. Soc. Inf. Sci. Technol. 2009, 60, 2229-2243. [CrossRef]

56. Bibi, F.; Khan, H.U.; Iqbal, T.; Farooq, M.; Mehmood, I.; Nam, Y. Ranking Authors in an Academic Network Using Social Network Measures. Appl. Sci. 2018, 8, 1824. [CrossRef]

57. Freeman, L.C. Centrality in social networks conceptual clarification. Soc. Netw. 1978, 1, 215-239. [CrossRef]

58. Adams, J.D.; Black, G.C.; Clemmons, J.R.; Stephan, P.E. Scientific teams and institutional collaborations: Evidence from U.S. universities, 1981-1999. Res. Policy 2005, 34, 259-285. [CrossRef]

59. Bordons, M.; Gómez, I. Collaboration networks in science. In The Web of Knowledge: A Festschrift in Honor of Eugene Garfield; Information Today Inc.: Medford, NJ, USA, 2000; pp. 197-213.

60. Glänzel, W. National characteristics in international scientific co-authorship relations. Scientometrics 2001, 51, 69-115. [CrossRef]

61. Laudel, G. Collaboration, creativity and rewards: Why and how scientists collaborate. Int. J. Technol. Manag. 2001, 22, 762. [CrossRef]

62. Australian Bureau of Statistics. Droughts, Fires, Cyclones, Hailstorms and a Pandemic-The March Quarter 2020. Available online: https: / / www.abs.gov.au/articles?page=5 (accessed on 28 July 2021).

63. King, A.D.; Pitman, A.J.; Henley, B.J.; Ukkola, A.M.; Brown, J.R. The role of climate variability in Australian drought. Nat. Clim. Chang. 2020, 10, 177-179. [CrossRef]

64. Tian, F.; Wu, J.; Liu, L.; Leng, S.; Yang, J.; Zhao, W.; Shen, Q. Exceptional Drought across Southeastern Australia Caused by Extreme Lack of Precipitation and Its Impacts on NDVI and SIF in 2018. Remote Sens. 2019, 12, 54. [CrossRef]

65. Kemter, M.; Fischer, M.; Luna, L.V.; Schönfeldt, E.; Vogel, J.; Banerjee, A.; Korup, O.; Thonicke, K. Cascading Hazards in the Aftermath of Australia's 2019/2020 Black Summer Wildfires. Earth Futur. 2021, 9, e2020EF001884. [CrossRef]

66. Bond, N.R.; Lake, P.S.; Arthington, A.H. The impacts of drought on freshwater ecosystems: An Australian perspective. Hydrobiologia 2008, 600, 3-16. [CrossRef]

67. van Dijk, A.I.J.M.; Beck, H.E.; Crosbie, R.S.; de Jeu, R.A.M.; Liu, Y.Y.; Podger, G.M.; Timbal, B.; Viney, N.R. The Millennium Drought in southeast Australia (2001-2009): Natural and human causes and implications for water resources, ecosystems, economy, and society. Water Resour. Res. 2013, 49, 1040-1057. [CrossRef]

68. Cobo, M.J.; Lopez-Herrera, A.G.; Herrera-Viedma, E.; Herrera, F. An approach for detecting, quantifying, and visualizing the evolution of a research field: A practical application to the Fuzzy Sets Theory field. J. Inf. 2011, 5, 146-166. [CrossRef]

69. Cobo, M.; López-Herrera, A.; Herrera-Viedma, E.; Herrera, F. Science mapping software tools: Review, analysis, and cooperative study among tools. J. Am. Soc. Inf. Sci. Technol. 2011, 62, 1382-1402. [CrossRef] 